AIAA 2001-3067

\title{
CFD SIMULATIONS IN SUPPORT OF SHUTTLE ORBITER CONTINGENCY ABORT AERODYNAMIC DATABASE ENHANCEMENT
}

\author{
P. E. Papadopoulos, ' D. K. Prabhu, ${ }^{\dagger}$ M. J. Wright, ${ }^{\ddagger}$ C. B. Davies, ${ }^{5}$ R. D. McDaniel, ${ }^{1}$ E. Venkatapathy, \\ ELORET, Sunnyvale, CA 94087 \\ P. Wercinski, ${ }^{\dagger \dagger}$ \\ NASA Ames Research Center, Moffett Field, CA 94035 \\ and \\ R. J. Gomez $z^{\text {tł }}$ \\ NASA Johnson Space Center, Houston, TX 77058
}

\begin{abstract}
$\underline{\text { Abstract }}$
Modern Computational Fluid Dynamics (CFD) techniques were used to compute aerodynamic forces and moments of the Space Shuttle Orbiter in specific portions of contingency abort trajectory space. The trajectory space covers a Mach number range of 3.5-15, an angle-of-attack range of $20^{\circ}-60^{\circ}$, an altitude range of $100-190 \mathrm{kft}$, and several different settings of the control surfaces (elevons, body flap, and speed brake). Presented here are details of the methodology and comparisons of computed aerodynamic coefficients against the values in the current Orbiter Operational Aerodynamic Data Book (OADB). While approximately 40 cases have been computed, only a sampling of the results is provided here. The computed results, in general, are in good agreement with the OADB data (i.e., within the uncertainty bands) for almost all the cases. However, in a limited number of high angle-of-attack cases (at Mach 15), there are significant differences between the computed results, especially the vehicle pitching moment, and the OADB data. A preliminary analysis of the data from the CFD simulations at Mach 15 shows that these differences can
\end{abstract}

-Senior Research Scientist. Member AIAA.

${ }^{+}$Senior Research Scientist. Senior Member AIAA.

${ }^{\ddagger}$ Research Scientist. Member AIAA.

'Senior Research Scientist.

IJunior Research Scientist. Member AIAA.

"President and Site Manager. Associate Fellow AIAA.

${ }^{*}$ Chief, Reacting Flow Environments Branch. Associate Fellow AIAA.

${ }^{\ddagger}$ Aerospace Engineer, Aeroscience and Flight Mechanics Division.

Copyright (C) 2001 by the American Institute of Aeronautics and Astronautics, Inc. No copyright is asserted in the United States under Title 17, U.S.Code. The U.S. Government had a royalty-free license to exercise all rights under the copyright claimed herein for Governmental purposes. All other rights are reserved by the copyright owner. be attributed to real-gas/Mach number effects. The aerodynamic coefficients and detailed surface pressure distributions of the present simulations are being used by the Shuttle Program in the evaluation of the capabilities of the Orbiter in contingency abort scenarios.

\section{Nomenclature}

$C_{p} \quad=$ Pressure coefficient

$C_{A}=$ Axial force coefficient

$C_{H B F}=$ Hinge moment coefficient (body flap)

$C_{H E I}=$ Hinge moment coefficient (inboard elevon)

$C_{H E O}=$ Hinge moment coefficient (outboard elevon)

$C_{H S B}=$ Hinge moment coefficient (speed brake)

$C_{m} \quad=$ Pitching moment coefficient

$C_{N} \quad=$ Normal force coefficient

$L_{B} \quad=$ Body length $(\mathrm{ft})$

$M \quad=$ Mach number

$\mathrm{Pr} \quad=$ Prandtl number

$q \quad=$ Dynamic pressure (psf)

$R e \quad=$ Unit Reynolds number $(1 / \mathrm{ft})$

Sc $=$ Schmidt number

$T=$ Static temperature $\left({ }^{\circ} \mathrm{R}\right)$

$V \quad=$ Velocity $(\mathrm{f} / \mathrm{sec})$

$Z \quad=$ Altitude $(\mathrm{ft})$

$x=$ Axial coordinate $(\mathrm{ft})$

$y=$ Span coordinate $(\mathrm{ft})$

$z=$ Normal coordinate $(\mathrm{ft})$

$\alpha \quad=$ Angle of attack $\left({ }^{\circ}\right)$

$\gamma \quad=$ Ratio of specific heats

$\Delta C_{m} \quad=$ Pitching moment coefficient increment

$\delta_{B F}=$ Body flap deflection $\left(^{\circ}\right)$

$\delta_{E} \quad=$ Elevon deflection $\left({ }^{\circ}\right)$

$\delta_{S B}=$ Speed brake deflection $\left(^{\circ}\right)$

$\phi \quad=$ Meridional angle $\left({ }^{\circ}\right)$

$\rho \quad=$ Mass density $\left(\right.$ slug $\left./ \mathrm{ft}^{3}\right)$

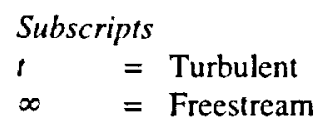




\section{Introduction}

Assessment of the Space Shuttle Orbiter performance during potential contingency abort scenarios is an essential element of future upgrades to improve the safety and reliability of the Shuttle fleet. Improving the Shuttle contingency performance is an important part of the overall Space Shuttle Orbiter safety improvement plan.' Orbiter abort scenarios are currently being re-examined to improve safety for Return to Launch Site (RTLS) aborts (see Fis. 1). The current two- and three-engine out trajectories for RTLS aborts include regions (black zones) where loss of the Orbiter and crew is predicted due to vehicle limitations and constraints (see Fig. 2). The opportunity to recover the crew and vehicle in these abort situations could be improved if the operational capabilities of the Orbiter outside of its nominal range were better understood. Therefore, a key to minimizing the black zones is to enhance our understanding of the aerodynamic capabilities of the Orbiter by providing better estimates of the aerodynamic loads the Orbiter would experience during abort scenarios.

Many design assumptions that were intended to provide the required margin of safety prior to the first Shuttle flights have been reassessed with improved tools and flight data. In addition, the performance limits of the Orbiter are now well established for nominal operating conditions. The aerodynamic environment of the current Orbiter is documented in the Orbiter Aerodynamic Data Book (OADB). " The OADB is primarily based on wind tunnel measurements extrapolated to flight conditions and updated with flight data where available. Much work was undertaken to validate the design aerodynamic database (i.e., the preflight aerodynamic database) with measurements from flights STS-1 through STS-5." After the first flight, the real-gas influence on the aerodynamic characteristics of the Orbiter at high Mach numbers was investigated fully including computational efforts of several researchers ${ }^{2}$ that accurately captured the flow physics in the nominal flight regime. The validity of the OADB is not in question for nominal flight conditions. The results from the present work, however, suggest that there are selected areas where the current OADB could be improved in off-nominal conditions, where the current data-book values have been extrapolated from wind tunnel and flight data. CFD has matured substantially since the original database was constructed and can now be used to evaluate and update the existing aerodynamic loads database.

Early RTLS trajectory assessment for contingency abort improvement requires aerodynamic loads in the freestream Mach number $\left(M_{*}\right)$ range of 6.0 to 15.0 and angles of attack $(\alpha)$ ranging from $20^{\circ}$ to $60^{\circ}$. The current loads (surface pressure distributions) database does not cover all of these conditions and is mostly limited to Mach 3.5 and below.

In order to establish the expanded aerodynamic database, full Navier-Stokes flow solvers were employed to predict aerodynamic loads on the Orbiter and its control surfaces. The scope of this paper is to outline the process used to compute and verify the CFD solutions that cover the required Mach number and angle-of-attack ranges for abort scenarios with a variety of control surface deflections. In addition, we show representative results for some of the cases and discuss reasons for occasional differences between current OADB data and the computations. A total of 31 cases were identified to cover Mach numbers from 3.5 to 15.0 , four angles of attack $\left(20^{\circ}\right.$ to $\left.60^{\circ}\right)$, three elevon/body flap combinations, and two speed-brake deflections. In addition, seven benchmark check cases were originally chosen to compare CFD results with available wind tunnel and flight data. An eighth benchmark case was added later.

Computation of the production aerodynamic loads was split between Boeing Reusable Space Systems (BRSS) and NASA Ames Research Center (ARC) while NASA Johnson Space Center (JSC) coordinated the effort. The Mach 3.5, 10.0, and 15.0 conditions were primarily a responsibility of ARC. The overall strategy implemented by $A R C$ to compute the contingency abort flight conditions uses methodologies derived from the X-33 program." The ARC team developed a set of automation tools to facilitate setting up cases, convergence and quality checks, and surface pressure and hinge moment data comparisons.

All results were presented to a review board consisting of experts in aerodynamics, structural analysis, Space Shuttle operations and CFD. This board (the Orbiter Aerodynamics Panel) reviewed the entire process to determine if the data was of sufficient quality to be released to the Orbiter structural analysts.

\section{Methodology}

The matrix of cases chosen to generate the necessary data, including the benchmark cases, is shown in Table 1. The benchmark cases include one wind tunnel case (OA-146) at Mach 3.5 and angle of attack of $18.5^{\circ}$, three flight cases at Mach 3.5, 6.0, and 15.0, and three additional flight cases at Mach 15.0 to complete an angle-of-attack sweep from $30^{\circ}$ to $60^{\circ}$. Although integrated aerodynamic forces and moments are available for the flight cases, only the comparison against the wind tunnel case will be presented in this 
paper. This case is critical because it also allows for surface pressure comparisons between the CFD and the experimentally measured values at data port locations on the wind tunnel model.

The production run matrix spans critical regimes of the contingency abort trajectories in the range of Mach numbers from 3.5 to 15.0 and angles of attack from $20^{\circ}$ to $60^{\circ}$. The Mach 3.5 and 6.0 cases include a speed brake deflected at $69.76^{\circ}$. The speed brake is not deflected for the higher Mach number cases. The matrix also includes negative and positive control surface deflections for both the elevons and the body flap. The Mach 3.5, 10.0, and 15.0 runs and a limited set of Mach 6.0 runs were calculated using the General Aerodynamic Simulation Program (GASP $)$.

In order to perform the simulations efficiently within a reasonable time and to assure the quality of the computations, an integrated process was developed with numerous check points to identify, capture and correct any potential mistakes. This process includes grid generation, CFD simulations and also the translation of the CFD data sets into data formats that can be readily used by the structural evaluation group. The overall approach is outlined in Fig. ? and consists of six phases: geometry certification and grid generation; CFD computations; post processing and analysis; conversion from CFD to Model Modal Loads and Structures (MMLS) format; aero analysis of MMLS formatted data sets; and the Orbiter Aerodynamics Panel review and approval. It is a requirement that the surface grid be certified as conforming to the Orbiter CAD definition provided by JSC. The initial grid generation phase includes the construction of surface and volume grids that topologically model the geometric details of the Shuttle Orbiter, including the control surfaces. A number of tools are available for analysis and verification. All computations are quality checked and cleared for postprocessing. Tools were created as necessary to bridge the gap between the CFD results and the formats required for structural analysis. The converted results are then used for aero analysis before review, approval and release to the structures group. Details of the general approach are discussed in the following sections.

\section{Geometry Verification and Simplification}

Grid generation is a time consuming process. The overall strategy implemented here addresses all the grid requirements outlined in the production run matrix (Table 1) for combinations of control surface deflections within the schedule constraints. The true surface representation for the Orbiter was provided by
JSC in CAD/IGES format. Individual surfaces were then stitched together and trimmed using HyperMesh ${ }^{10}$ to provide a single "water tight" surface definition for the grid generation process. The resulting surface was then triangulated, capturing all of the geometric details, including control surfaces, engines and nozzles in the base region. The requirements for the surface grid are (1) conformity of the triangulation to the CAD surface, and (2) grid smoothness. The surface grid was compared against the IGES by JSC and the wing root section near the fuselage-to-wing glove-fairing surface was found to deviate from the true surface. This tolerance error was introduced during the trimming process of the wing surfaces against the fuselage surfaces. A corrective action was taken to locally refine the surface grid and project it on the CAD geometry. The surface grid was then judged to conform to the CAD geometry and was certified for CFD simulations by JSC.

At this point, certain geometric simplifications were made that facilitated the grid generation process without sacrificing solution fidelity. Regions where the Orbiter geometry was approximated are highlighted in $\mathrm{Fig}_{\mathrm{g}}$. $\mathrm{A}_{\mathrm{a}}$ and detailed views are shown in Fivs. $4 \mathrm{~b}-\mathrm{e}$. The true geometry at the wing tip (Tis. 4 b) is characterized by a backwards-facing step. To resolve the local flow phenomena, a local topological substructure would have been required. The contribution of this local flow structure on the global aerodynamics was assumed to be negligible. An edge-fairing surface was used to suppress this geometric detail and locally idealize the geometry as shown in Fig. 4c. For the low Mach number cases ( 3.5 and 6.0 ) the speed brake is deflected which would expose a gap on both sides of the control surface. As shown in 1, th a gap fairing filler surface is used to cover the gap regions, which permits the same topology to be used for both the undeflected and deflected speed brake. The surface grid accurately captures the speed brake thickness and curvatures on either side at the tip of the control surface. The last geometric approximation is highlighted in Fig. 4:. All the geometric details and the engine nozzles in the base region were simplified with a shroud cover. It is important to note that the windward, side, and trailing edge surfaces of the body flap are exactly preserved. In the base region the local pressure is expected to be orders of magnitude lower in comparison to the pressure on the windward side of the vehicle, which is the main contributor to aerodynamic forces and moments. Unpublished solutions obtained using the USA code "with all the geometric details in the base region, are used to assess this geometric simplification. 


\section{Volume Grid Generation}

For volume grid generation, a strategy was adopted to provide grids for a large number of high-fidelity solutions that have differing grid requirements for control surface deflections and angles of attack. The grid generation tools used were GridPro" and Gridgen." GridPro was used to build the complex topological structure and Gridgen was implemented for local grid modifications. The volume grid consists of three topological layers: the inner, intermediate, and outer. The inner layer shown in $\mathrm{Fig}_{\mathrm{i}} \mathrm{s}_{\mathrm{a}}$ was designed to capture the boundary layer and contain the topological structure around all the control surfaces. Localized topologies were built in this layer to allow for deflection of the control surfaces by local substitution without manipulating the overall volume grid. In the inner layer, the normal clustering and the number of points can be adjusted as needed to capture the viscous gradients without altering the overall volume grid. The intermediate layer shown in Fig. Sh reflects the topological complexity due the surface geometry. Most of the complexity is in the aft part of the vehicle associated with the deflected speed brake and elevons. A strategy was developed to degenerate and redirect topological complexity away from the nose of the vehicle where regions of high grid density associated with the control surfaces should not propagate. The outer layer shown in $\mathrm{Fig} .5 \mathrm{c}$ was designed to efficiently contain the bow shock for each angle-of-attack. Modifications to the outer layer grid, related to changes in angle of attack, do not disturb the other layers. Miguri 6 it highlights the surface grid smoothness on the wing, as well as the strategy of redirecting grid points from the inner elevon gap region to the outer elevon gap. Figure bb shows the inner grid layer where the grid density normal to the surface and distributions could be adjusted accordingly to capture the viscous layer. Figure $6 c$ highlights the localized topology where local volume grids for deflected control surfaces could be replaced. The final grid is comprised of 365 elementary blocks (see Figs, $7 \mathrm{a}, \mathrm{h}$ ) that are merged down to 38 point-wise matching zones, and contains about 2.2 million grid points. It was later determined that a wake grid was required for the high angle-of-attack $\left(50^{\circ}\right.$ and $60^{\circ}$ ) cases in order to contain the subsonic portion of the wake flow. This grid was built using Gridgen and added 1.4 million points to the volume grid.

\section{CFD Simulations}

The GASP code solves the full Navier-Stokes equations using finite volume spatial discretization. GASP includes a wide selection of physical models and numerical algorithms. Physical model selections are based on the free-stream conditions, and the choice of numerical algorithm is based on grid topology and sensitivity studies performed previously." "The idealgas model $(\gamma=1.4)$ is used for cases up to Mach 6.0. For higher Mach numbers, real-gas effects are important and are modeled using Park' $s^{1 \text { ? }}$ five-species air model and finite-rate chemistry. The inviscid fluxes are computed using third-order Van Leer flux vector splitting with the min-mod limiter. The discretized system of equations is advanced to a steady state using two-factor approximate factorization. For all turbulent cases, the Baldwin-Lomax turbulence model ${ }^{-4}$ (with compressibility corrections') is used. The implemented physical models and numerical algorithms are organized in Table 2. GASP has been applied successfully in the past to predict aerothermal environments for the Shuttle Orbiter, X-33, X-34, X-38, Mars Pathfinder, Mars' 03 and other planetary mission studies. GASP has been a very useful tool in relating facility measurements to flight and in providing insights into viscous, real-gas, and Mach number effects. In addition, $G A S P$ simulations performed for wind tunnel conditions $\left(M_{\alpha}=6.0\right.$ and $\left.M_{\alpha}=20.0\right)$ for the X-38 vehicle predicted aerodynamics well."

\section{Post-Processing}

Global aerodynamics were extracted from the computed solutions by integrating pressure and shear stress over the Orbiter surface. Certain quantities, notably pitching moment in a near-trim attitude, are extremely sensitive to interpolation errors and other biases during extraction of the aerodynamic forces and moments, and care must be taken to eliminate these errors from the integration. For example, early in the project there was a one-inch error (less than $0.1 \%$ of vehicle length) in the stream-wise location used for the moment reference center. This changed the computed pitching moment by as much as $12 \%$ near trim conditions. Control surface aerodynamics were extracted in a similar manner, with the integration occurring over only that subset of the surface grid that defines the control surface.

Historically, a stumbling block in the communication between the CFD and structural design communities has been the difficulty of transforming CFD solution data into a format appropriate for practical vehicle design. In this project, a format that could be used by the MMLS suite of codes was requested by the Aero and Structures groups. Values of surface pressure coefficient $\left(C_{n}\right)$ were to be provided at the fixed locations (data ports) on the Orbiter surface. For design requirements the vehicle data ports are grouped into four segments: the fuselage; upper and lower wings; and the vertical tail; with each referenced to their own local coordinate system. The provided 
locations of the data ports were mapped onto the actual Orbiter surface, and the resulting locations were verified by the structures team. Although there were some initial problems with locating points appropriately on control surface leading and trailing edges, these issues were resolved after a few iterations between the CFD and structures teams. The CFD data were then interpolated to the final data-port locations using an inhouse tool, and the resulting data were compared to the original CFD solutions to ensure that the interpolation was accurate.

\section{Results}

\section{Grid Resolution}

All CFD simulations using GASP were performed on two levels of grid refinement. The grid sequencing strategy was limited by the multi-block structure. The complex topology necessitated coarsening the grid in all three coordinate directions simultaneously. As a result, the coarse and fine grids differ by a factor of eight in grid density. The coarse grid level (Fis. contains 275 thousand points and the fine grid ( $F i s .8 \mathrm{~S}$ ) has 2.2 million points. Figure $s c$ shows computed surface pressure coefficient on both grids for the Mach $10, \alpha=40^{\circ}$ case. From the figure we see that both grids produce very similar $C_{p}$ distributions. Also shown in Fis. $x_{c}$ are the integrated axial $\left(C_{A}\right)$ and normal $\left(C_{N}\right)$ force and pitching moment $\left(C_{m}\right)$ coefficients on the two sequence levels. Differences in the normal force and pitching moment coefficients are very small. The largest difference is observed in the computed axial force. This result is not surprising since the coarse grid has half the resolution in the surface-normal direction. As a result, the viscous contributions to the axial force are over predicted on the coarse grid.

As a standard practice, all the CFD solutions are checked for steady-state convergence. In addition to continuously monitoring the residual, the integrated loads and moments are checked at regular intervals. The solution is converged when the integrated loads and moments reach asymptote values and no longer change. A more detailed convergence check is performed by monitoring changes in surface $C_{p}$ distribution. Differences are taken between calculated surface $C_{p}$ distributions every four hundred iterations and images are generated to look for asymptotic convergence. This process is illustrated in Fig. 9 for the Mach 3.5, $\alpha=18.5^{\circ}$ benchmark case. The maximum difference in $C_{p}$ on the wind and lee surfaces between solutions four hundred iterations apart is less than 0.001 .

\section{Base Contributions}

The impact of the base geometry approximation on aerodynamic forces and moments is addressed here. Figure loa shows a schematic of the ARC approximated base geometry. All the geometric details in the base region, including the engine nozzles, were replaced by a shroud cover. The justification for this simplification is that the base region is exposed to pressure levels that are orders of magnitude lower than the windward pressures. Therefore, the wind-side pressure distribution is the main contributor to the integrated loads and moment coefficients. In order to quantify the effect of this simplification, base corrections to all global aerodynamic quantities were extracted from USA solutions (computed by the BRSS team; not discussed in this paper), which included all of the geometric details in the base region. The effect of the base simplification is discussed here only in terms of the integrated moment coefficient. The effect on other aerodynamic coefficients is much smaller. Figures $10 \mathrm{~b}, \mathrm{c}$ : show pitching moment as a function of angle of attack for a constant Mach number including the shuttle data-book values (solid lines) along with their reported uncertainty (dashed lines). The solid circles represent the pitching moment values that exclude the contribution from the approximate base geometry, i.e., the surface aft of the solid line in Tig. 10,2. The solid triangles represent the pitching moment values that include the contribution from the approximate base geometry. The open circles are the GASP results that have been "corrected" to include a base contribution taken from the corresponding USA solution. In Iis. loh, comparisons are shown for the Mach 3.5 case, since the base contribution is anticipated to be larger at lower Mach numbers. Firur lob shows that the differences are small and that the base correction tends to push the computed pitching moment toward the OADB values. Figure $10 \mathrm{k}$ shows the same comparison for the highest Mach number case. In this case, the base contribution to the overall integrated moment is negligible. This assessment re-affirms that the geometric simplifications in the base region do not sacrifice solution quality. It is important to clarify here that although the base geometry was simplified, the high angle-of-attack cases $\left(50^{\circ}\right.$ and $\left.60^{\circ}\right)$ were computed with a wake grid. A wake grid was necessary for these cases to provide the appropriate boundary conditions to capture the flow physics as the flow expands rapidly from the windward side into the base region. For all the low angle-of-attack cases $\left(20^{\circ}-40^{\circ}\right)$ a wake grid was not included in the computation. For these cases it was effectively assumed that the base contribution to aerodynamic forces and moments is zero. 
Comparison of the individual cases with the $O A D B$ provided a basis to look at the CFD simulations more closely. For most cases, the solutions were in good agreement with the OADB, and were deemed acceptable once they had passed the internal quality review. In those cases where there were observable differences, the CFD simulations were first re-evaluated and then re-analyzed to understand the cause of the differences. In addition, the origin and makeup of the $O A D B$ for these cases were reviewed to determine the fidelity of the data book for nominal and off-nominal conditions. In the following sections we present sample results and focus on a flight regime where CFD predicts interesting results.

\section{Mach 3.5 Computations}

All Mach 3.5 cases, except for the $-15^{\circ}$ (trailing edge up) elevon deflection cases, shown in the production run matrix (Tible 1) were computed successfully using the GASP code and the results were compared against the data-book values. The Mach 3.5, $\delta_{E}=-15^{\circ}$ cases were not computed due to schedule constraints. Instead an existing volume grid for the $-10^{\circ}$ elevon deflections was used to compute the Mach 3.5 schedule B $\left(40^{\circ}-60^{\circ}\right)$ cases. An extrapolation scheme has been established based on experimental data and CFD $\left(\delta_{E}=-10^{\circ}\right)$ to provide integrated forces and moments as required for those cases. A representative set of cases for the Mach 3.5 schedule B angle-of-attack sweep is shown in Fis. 14 . For the cases presented, both the elevon and body flap control surfaces are undeflected. The speed brake is deployed to $69.76^{\circ}$. The comparisons are very good in general. Trends follow the data book and comparisons are on or within the uncertainty bands for the normal $\left(C_{N}\right)$ and axial $\left(C_{A}\right)$ forces, pitching moment $\left(C_{m}\right)$ coefficients and control surface hinge moments, inner elevon $\left(C_{H E I}\right)$, outer elevon $\left(C_{H E O}\right)$, and body flap $\left(C_{H A F}\right)$. Table 4 summarizes the comparisons of all force and moment coefficients including hinge moments for all control surfaces for the cases shown in 17g. 14. In Table 4 the moment coefficient for the Mach 3.5, $\alpha=50^{\circ}$ with undeflected elevons and body flap and the $\alpha=50^{\circ}, \delta_{E}=$ $-10^{\circ}$ cases are marked with marginal acceptability but are sufficiently close to the data-book values for the contingency abort loads assessment purposes. The same classification was also given to the Mach 3.5, $\alpha=60^{\circ}$, $\delta_{E}=-10^{\circ}$, undeflected body flap $\left(\delta_{B F}=0^{\circ}\right)$, elevon hinge moment comparisons. Significant differences are observed for the body flap hinge moments at the $\alpha=$ $50^{\circ}$ and $60^{\circ}, \delta_{B F}=-11.7^{\circ}$ cases. For these cases the global force and moment comparisons are very good and local differences in the body flap region are related to strong windward side sonic flow at high angles of attack. Detailed investigations are currently underway to understand the precise nature of these differences.

\section{Mach 6 Computations}

The forces and moments at Mach 6 are compared to the data-book values in Fir. 15. The cases presented here correspond to undeflected elevons and body flap. The speed brake is deflected to $69.76^{\circ}$. The angle-ofattack sweep shown corresponds to schedule $C$ $\left(20^{\circ}-60^{\circ}\right)$. The overall comparisons between the computations and the OADB values are excellent. The CFD computations capture the pitching moment vs. angle-of-attack slope change (cusp) that occurs at $50^{\circ}$, consistent with the OADB measured values. For these high angle-of-attack conditions the flow in large portions of the windward side shock layer becomes subsonic and as a result the pressure distribution changes. This significantly changes aerodynamic characteristics of the Orbiter, which is evident in the integrated aerodynamics by the cusp shown in $1 \mathrm{is} .15 \mathrm{~K}$. More details on this phenomenon will be presented later in this paper. The comparison summary is shown in Tahle 5. All Mach 6.0 data were accepted by the Orbiter Aerodynamics Panel, including the speed brake hinge moment value at $\alpha=20^{\circ}$ where the data were identified as marginally acceptable for assessment purposes.

\section{Mach 10 Computations}

A single case at Mach 10.0 was included in the production run matrix to provide an anchor point at $\alpha=$ $40^{\circ}$ where flight data exist. This check case was computed using GASP to compare with OADB integrated forces and moments and to verify Mach trends. The results are shown in Figs. 16a-g. The integrated aerodynamics were found to be in good agreement with the data book. CFD results were reasonable both in magnitude and Mach trends.

\section{Mach 15 Computations}

In order to assess the sensitivity of the computed solutions to the choice of transport models at Mach 15 , turbulent flow simulations were performed at $\alpha=30^{\circ}$ and $40^{\circ}$ in addition to laminar simulation for all angles of attack. The Baldwin-Lomax turbulence model with compressibility corrections ${ }^{+}$was used in the computations. Since GASP does not currently possess the ability to model transition, the flow was assumed to be fully turbulent from the tip of the nose. Table 6 shows the computed aerodynamic coefficients for the two angles of attack. Compared to the corresponding aerodynamic coefficients from the laminar 
computations, turbulent predictions show substantial increases in the axial force coefficients and small changes in the normal force coefficients. Further, the small changes in pitching moments are "stabilizing" (i.e., increasingly negative compared to the OADB mean values). The observed changes are not wholly unexpected. The assumption of fully developed turbulence at the nose of the vehicle is questionable. It must be borne in mind that at Mach 15, the unit Reynolds number (based on free stream quantities) is small $(-34,000 / \mathrm{ft})$ and turbulence is not expected to develop as far forward as the nose of the vehicle. Transition would occur, if at all, towards the aft of the vehicle. Given that the center of gravity of the vehicle is located far aft, the moment contributions from the nose region of the vehicle can be very large due to the large moment arm. Any significant increases in the shear load in this region will lead to large increases in the computed moment. Any increases aft would probably have a smaller impact due to the shorter moment arm to the center of gravity of the vehicle. The assumption of a laminar flow is bolstered by the fact that at $\alpha=40^{\circ}$, the predicted force and moment coefficients are in good agreement with the OADB values which are extracted from the Shuttle flights.

In addition to the turbulent results, Table 6 shows the contributions of the non-viscous (pressure only) terms to the aerodynamic forces and moments for the laminar cases. It is evident from the tabulated results that the viscous contributions to the forces and moments are very small with the sole exception of the axial force. The contribution of the wall-bounded shear layer to the axial force is significant as expected.

Based on these sensitivity studies, all of the Mach 15 cases were computed assuming the flow to be laminar. The additional discussion of the Mach 15 cases that follows is based on the computed laminar solutions (either ideal-gas or real-gas model).

CFD to OADB comparisons of results of select cases from the Mach 15 production run matrix (shown in Table 1) are presented in Figs. 17a-i. The integrated loads and moments are plotted against the schedule $A$ $\left(30^{\circ}-60^{\circ}\right)$ angle-of-attack range. The comparisons are very good in general, and the computed values are on or within the uncertainty bands. The computed data follow the $O A D B$ trends except for the integrated pitching moment coefficient $\left(C_{m}\right)$ at $\alpha=60^{\circ}$. For this particular case, GASP predicts a more negative (nose down) pitching moment and is divergent from the OADB value. The $O A D B$ trend shows the cusp that was seen earlier in the Mach 3.5 and Mach 6 data. For the Mach 3.5 and 6 computations, the cusp was captured by the CFD and comparisons with the OADB data were very good. Therefore, it was puzzling that the CFD seemed unable to capture the similar trend at the higher Mach number. Further studies were undertaken to resolve these differences between the computed results and the $O A D B$ values and the results of these studies are presented and discussed in the next section.

The comparison summary for all the Mach 15 cases is shown in Table 7. All Mach 15 data were accepted by the Orbiter Aerodynamics Panel, including the $\alpha=60^{\circ}$ pitching moment values discussed below.

High Angle of Attack Comparison at Mach 15

In the previous section, the results of the Mach 15 computations were presented (see Ficrs 17/-1). The computed results, with the exceptions of the vehicle normal force and pitching moment coefficients at an angle of attack of $60^{\circ}$, compare favorably (i.e., within the uncertainty bands) with the OADB. At $\alpha=60^{\circ}$, however, the computed pitching moment is found to be more "stabilizing" (i.e., more negative or nose down) as compared to the OADB. Further, the cusp (or a pitching moment reversal) in the OADB pitching moment curve (see Fig. I. . ) beyond $\alpha=50^{\circ}$ is not reproduced by the computed results. The large negative value of the predicted pitching moment at $\alpha=60^{\circ}$ means that a large restorative (nose up) aerodynamic force would be required in order to trim the vehicle at this angle of attack. This restorative force is much larger than that required using the $\mathrm{OADB}$ value of the pitching moment. It is interesting to note that the results of computations performed at Mach 3.5 and 6 agree very well with the OADB values and, more importantly, show the same trends as the OADB up to and including $\alpha=60^{\circ}$.

In Figs. I $8 \mathrm{a}-\mathrm{b}$, the pitching moment coefficient is plotted as a function of Mach number for angles of attack of $40^{\circ}, 50^{\circ}$ and $60^{\circ}$, respectively. At $\alpha=40^{\circ}$ (Fig. 18it), the pitching moment trend is in excellent agreement with that of the OADB. Again at $\alpha=50^{\circ}$ (Fig. 1 $\mathrm{Xl}$ ) the trend is in good agreement with the OADB. At $\alpha=60^{\circ}$ (Fis 18\%), however, the computed pitching moment trend in Mach number is opposite to that of the OADB beyond Mach 6 . The results of a preliminary investigation into resolving this aerodynamic behavior at $\alpha=60^{\circ}$ is now presented.

We begin by examining the $O A D B$ data at high Mach numbers and angles of attack. The OADB mainly consists of pre-flight aerodynamic data gathered from extensive wind tunnel testing from either ideal-gas (air) facilities (for Mach 3.5 and 6.0) or inert-gas (He) facilities (for Mach 18-20). These basic data are supplemented with - (a) results of best available theory 
(to account for, among others, viscous, Mach number, high-altitude, and real-gas effects), and (b) data from the various Orbiter flights. The supplemental data are added as increments to the basic pre-flight (ideal-gas) values. For example, the pitching moment coefficient can be written as a basic term $\left(C_{m \text {-BASIC }}\right)$ plus increments due to various effects, i.e.,

$C_{m \cdot O A D B}=C_{m \cdot B A S I C}+\Delta C_{m \cdot \text { Real Gas }}+\Delta C_{m \cdot \text { Viscous Interations }}+$ $\Delta C_{m \cdot \text { High Altitule }}+\ldots$

$C_{m \cdot B A S I C}$ is extracted from ground-based measurements and extrapolated across the Mach number range. This extrapolation leads to large uncertainties in the OADB data. Note that any narrowing of the uncertainty bands in the aerodynamic coefficients reflects the use of flight data in the $O A D B$. The pitching moment increment due to real-gas effects ( $\Delta C_{m \text {-Resl Gas }}$ as used in the OADB) at Mach 15 for $\alpha=40^{\circ}$ is +0.022 and is in fairly good agreement with that predicted using the GASP code $(+0.0248)$ at the same angle of attack.

It is important to note that - (1) no flight data exist at $50^{\circ}$ and $60^{\circ}$ angles of attack (however such angles do occur at points on the contingency abort candidate trajectories), and (2) the Orbiter is currently certified to fly at angles of attack less than $44^{\circ}$ at Mach 15.

The reversal in pitching moment at high angles of attack occurs when the shock-layer becomes subsonic over a large portion of the windward side of the vehicle. In Fig. 19 the sonic lines for the Mach 3.5 cases (for $\alpha=40^{\circ}, 50^{\circ}$, and $60^{\circ}$ ) are shown for the pitch plane of the vehicle. The sonic line attachment point moves aft with increasing angle of attack and at the highest angle of attack $\left(60^{\circ}\right)$, the sonic line anchors close to the trailing edge of the body flap. Further, at this angle of attack, the flow on the windward side of the vehicle is almost entirely subsonic as is expected. The CFD simulations at this Mach number match the behavior of the pitching moment data in the OADB. A similar pitch plane plot is shown for Mach 6 in Fig. 20. Again, the rearward movement of the sonic line is seen with increasing angle of attack. Further, the CFD simulations duplicate the pitching moment reversal at this Mach number. Note that all of the Mach 3.5 and 6 cases were computed using an ideal-gas model. Recall that the Mach 15 cases were computed using a real-gas model. To better understand the nature of real-gas effects at high angles of attack, the ideal-gas model was therefore used to compute additional solutions at Mach 15 for an angle-of-attack range of $30^{\circ}-70^{\circ}$. In Fig. 2I the sonic lines for these Mach 15 cases are shown for the pitch plane of the vehicle. Again, the rearward movement of the sonic line attachment point is clearly seen. Further, at $\alpha=60^{\circ}$ and $70^{\circ}$, a substantial portion of the windward shock layer is subsonic. For $\alpha=60^{\circ}$, the sonic lines for Mach 3.5, 6, and 15 ideal-gas cases are shown in Fig. 22. The impact of Mach number is clearly seen - the sonic line attachment point moves forward with increasing Mach number. In Fig. 23, the sonic lines in the pitch plane are shown for the real-gas cases at Mach 15. At $\alpha=60^{\circ}$ the sonic line does not attach as far aft on the vehicle as is observed in the ideal-gas computations. In the real-gas computations, the windward side of the vehicle develops a smaller subsonic zone (the sonic lines attach closer to the nose) and consequently, a pitching moment reversal is not observed in the computed results. The nature of the shock layer in the real-gas case is quite different from that in the ideal-gas case - the bow shock is closer to the body (thinner shock layer). The effect of the physical model (real vs. ideal) on the integrated pitching moment variation with angle of attack at Mach 15 is shown in Fig. 24.

\section{Mach 15 Conclusions}

The real-gas predictions of the pitching moment are within the uncertainty band of the $O A D B$ up to an angle of attack of $50^{\circ}$ with excellent agreement with flight data at $\alpha=40^{\circ}$. While the real-gas computations do not exhibit the pitching moment reversal at high angles of attack, results of computations based on the ideal-gas model do. A more detailed investigation of real-gas effects is currently underway. While the observations made above are limited to Mach 15, what is not clear is whether the same trends will hold across the entire Mach number range where real-gas effects are important. In addition to Mach number and real-gas effects, the freestream density (or equivalently, the altitude) has an important role. The results from the present work suggest that the OADB could be improved or enhanced in the hypersonic, high angle-of-attack regime, an important regime from the point of view of contingency aborts.

\section{Summary and Recommendations}

The general comparison between the computed integrated forces, moment coefficients and hinge moments against the OADB is summarized in Tahles 4 , 5 , and 7 for the Mach 3.5, 6.0, and 15.0 sets of cases, respectively. The overall agreement is very good. The majority of the computed data is typically inside or near the OADB uncertainty bands, and follow similar trends. In general, the computed moment coefficients are consistently lower than the $\mathrm{OADB}$ values, the normal force coefficients consistently higher, and the axial force coefficients typically agree very well. The Mach $15, \alpha=60^{\circ}$ pitching moment characteristics have been 
discussed and differences between the CFD and the OADB trends were justified. All of the CFD-generated airloads have been released for structural analysis.

The Mach 10 and 15 computations and comparisons to OADB data clearly demonstrate that real-gas computational methods are essential for high Mach number aerodynamic predictions. The production run cases computed by ARC resulted in reasonable agreements and close predictions consistent to the OADB values and trends. This general agreement points to increased confidence in the CFD process to predict aerodynamics in regimes where limited experimental and flight data exist. It also provides critical insights into physical phenomena such as Mach number, real-gas and viscous effects. This confidence level in the CFD data allows for a deeper understanding of the physics involved and tighter integration between wind tunnel, flight, and numerical data.

This work has provided the post-processing tools for translating CFD results into formats useful by other disciplines in aerodynamic and structural analysis.

The final recommendation of the working group was to release the CFD data generated for abort assessment and further aerodynamic and structural analysis. The detailed CFD process and computed results presented here were extensively reviewed by the Orbiter Aerodynamics Panel. The quality of the data was recognized by the review board and approved for release.

\section{Acknowledgements}

The first 6 authors (PEP, MJW, DKP, CBD, RDM, and EV) were supported by NASA Ames Research Center, through contract NAS2-99092 to ELORET. The authors would like to thank the BRSS Team of Kurian Mani, Jeffrey Bennett, Jeffrey Stone, and Sergio Carrion for their support, interchange of ideas, and providing their computed results. The authors would also like to thank: James Brown (NASA ARC) and Michael Tauber (ELORET) for their high angle-ofattack computations for an elliptic cone which provided good insight in accomplishing the high alpha cases presented in this work; John Melton (NASA ARC) for his efforts in computing the production and benchmark cases using the TIGER code; Mark Loomis (NASA $A R C$ ) and Yehia Rizk (NASA ARC) for their valuable suggestions/insights; Dean Kontinos (NASA ARC) and Grant Palmer (ELORET) for their critical evaluation of the computed results; and the Orbiter Aerodynamics Panel (headed by Rick Barton of NASA JSC) of the Shuttle Contingency Abort Program for their comments/ suggestions.

\section{References}

1 Ondler, M., "Abort Improvement Team Recommendation," PRCB SR 1145A, NASA Johnson Space Center, Dec. 1999.

2 Boeing, Human Space Flight and Exploration, Huntington Beach, CA, "Operational Aerodynamic Data Book," Boeing Document STS85-0118 CHG 9, 2000 .

3 Orbiter Experiments (OEX) Aerothermodynamics Symposium, Ed. D. Throckmorton, NASA CP-3248, Parts 1 and 2, April 1995.

${ }^{4}$ Papadopoulos, P.E., Venkatapathy, E., Prabhu, D., Loomis, M.P., Olynick, D., "Current Grid-Generation Strategies and Future Requirements in Hypersonic Vehicle Design, Analysis and Testing," Applied Mathematical Modelling, Vol. 23, pp. 705-735, 1999.

5 Prabhu, D.K., Loomis, M.P., Venkatapathy, E., Polsky, S., Papadopoulos, P., Davies, C.B., and Henline, W.D., "X33 Aerothermal environments Simulations and Aerothermodynamic Design," AIAA Paper 98-0868, Jan. 1998.

${ }^{6}$ Prabhu, D.K., Wright, M.J., Marvin, J.G., Brown, J.L., and Venkatapathy, E., "X-33 Aerothermal Design Environment Predictions: Verification and Validation," AIAA Paper 2000-2686, June 2000.

${ }^{7}$ Chakravarthy, S.R., Szema, K.Y., "Unified 'Nose-toTail' Computational Method for Hypersonic Vehicle Applications," AIAA Paper No. 88-2564, 1988

${ }^{8}$ Chakravarthy S.R. and Osher S., "Computing with High-Resolution Upwind Schemes for Hyperbolic Equations," Proceedings of the 1983 AMS-SIAM Summer Seminar on Large-Scale Computations in Fluid Mechanics, published by American Mathematical Society in Lectures in Applied Mathematics, Vol. 22, 1985.

9 AeroSoft, Inc., 1872 Pratt Drive, Suite 1275 , Blacksburg, VA 24060-6363, GASPex Version 3 User's Manual, 1997.

${ }^{10}$ Altair Computing, Inc., 1757 Maplelawn Drive, Troy, MI 48084, HyperMesh 2.I User's Manual, 1997.

"Program Development Corp., 300 Hamilton Avenue, Suite 409, White Plains, NY 10601, GridPro/az3000 User's Guide and Reference Manual, 1996. 
${ }^{12}$ Pointwise, Inc., PO Box 210698, Bedford, TX 76095 7698, Gridgen User Manual, version I3, 1997.

${ }^{13}$ Park, C., "A Review of Reaction Rates in High Temperature Air," AIAA Paper 89-1740, June 1989.

14 Baldwin, B.S., and Lomax, H., "Thin Layer Approximation and Algebraic Model for Separated Turbulent Flows," AIAA Paper 78-257, Jan. 1978.

${ }^{15}$ Loomis, M.P., Venkatapathy, E., Papadopoulos, P., Davies, C.B., Berry, S., Horvath, T., Campbell, C., "Aeroheating and Aerodynamic CFD Validation and Prediction for the X-38 Program," AIAA Paper 97 2478, June 1997.
${ }^{16}$ Marroquin, J., "Results of a Wind Tunnel Pressure Loads Test of the 0.03-Scale Space Shuttle Orbiter

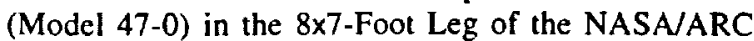
Unitary Plan Wind tunnel (OA146)," Rockwell International Space Transportation \& Systems Group, NASA-CR 167652, Vol. 1, Jan. 1983.

17 Romere, P.O., Brown, S.W., "Documentation and Archiving of the Space Shuttle Wind Tunnel Test Data Base," NASA-TM 104806, Vols. I and 2, Jan. 1995. 
Table 1 Benchmark and production airloads run matrix

\begin{tabular}{|c|c|c|c|c|c|c|}
\hline \multicolumn{7}{|c|}{ Benchmark Cases } \\
\hline$M_{\infty}$ & $\alpha$ & $\delta_{E}$ & $\delta_{B F}$ & $\delta_{S B}$ & \# of Cases & ARC \\
\hline 3.5, STS-93 Flt. & 18.5 & $0^{\circ}$ & $+11^{\circ}$ & $69.76^{\circ}$ & 1 & 1 \\
\hline $3.5, \mathrm{OA}-146$ & 18.5 & $0^{\circ}$ & $+11^{\circ}$ & $69.76^{\circ}$ & 1 & 1 \\
\hline $3.5, O A-146$ & 23.2 & $0^{\circ}$ & $+11^{\circ}$ & $69.76^{\circ}$ & $l$ & $I$ \\
\hline 6, STS-93 Flt. & 28.5 & $0^{\circ}$ & $+11^{\circ}$ & $69.76^{\circ}$ & 1 & 1 \\
\hline $15, \mathrm{OADB}$ & $A^{a}$ & $0^{\circ}$ & $+11^{\circ}$ & $0^{\circ}$ & 4 & 2 \\
\hline \multicolumn{5}{|c|}{ Total number of benchmark cases } & $7[+1]$ & $5[+1]$ \\
\hline \multicolumn{7}{|c|}{ Production Cases } \\
\hline$M_{\infty}$ & $\alpha$ & $\delta_{E}$ & $\delta_{B F}$ & $\delta_{S B}$ & \# of Cases & ARC \\
\hline 3.5 & $\mathrm{~B}^{\mathrm{h}}$ & $0^{\circ}$ & $0^{\circ}$ & $69.76^{\circ}$ & 3 & 3 \\
\hline 3.5 & B & $0^{\circ}$ & $-11.7^{\circ}$ & $69.76^{\circ}$ & 3 & 3 \\
\hline 3.5 & B & $-15^{\circ}\left(-10^{\circ}\right)$ & $0^{\circ}$ & $69.76^{\circ}$ & 3 & 3 \\
\hline 6 & $\mathbf{C}^{\mathrm{c}}$ & $0^{\circ}$ & $0^{\circ}$ & $69.76^{\circ}$ & 5 & 5 \\
\hline 6 & $\mathrm{C}$ & $0^{\circ}$ & $10^{\circ}$ & $69.76^{\circ}$ & 5 & \\
\hline 6 & $\mathrm{C}$ & $10^{\circ}$ & $0^{\circ}$ & $69.76^{\circ}$ & 5 & \\
\hline 6 & C & $-10^{\circ}$ & $0^{\circ}$ & $69.76^{\circ}$ & 5 & \\
\hline 10 & 40 & $0^{\circ}$ & $0^{\circ}$ & $0^{\circ}$ & 1 & 1 \\
\hline 15 & $\mathbf{A}$ & $\mathbf{0}^{\circ}$ & $0^{\circ}$ & $0^{\circ}$ & 4 & 4 \\
\hline 15 & A & $0^{\circ}$ & $10^{\circ}$ & $0^{\circ}$ & 4 & 4 \\
\hline 15 & A & $-10^{\circ}$ & $0^{\circ}$ & $0^{\circ}$ & 4 & 4 \\
\hline 15 & $\mathrm{~A}$ & $10^{\circ}$ & $0^{\circ}$ & $0^{\circ}$ & 4 & 4 \\
\hline \multicolumn{5}{|c|}{ Total number of production cases } & 46 & 31 \\
\hline \multirow{3}{*}{\multicolumn{5}{|c|}{$\begin{array}{l}\text { Total number of cases } \\
\text { 'A Schedule: } \alpha=30^{\circ}, 40^{\circ}, 50^{\circ} \text {, and } 60^{\circ} \\
\text { 'B Schedule: } \alpha=20^{\circ}, 30^{\circ}, 40^{\circ}, 50^{\circ} \text {, and } 60^{\prime} \\
\text { 'C Schedule: } \alpha=40^{\circ}, 50^{\circ} \text {, and } 60^{\circ}\end{array}$}} & $53[+1]$ & $36[+1]$ \\
\hline & & & & & & \\
\hline & & & & & & 9 \\
\hline
\end{tabular}

Table 2 Physical models and numerical algorithms implemented in $G A S P$

\begin{tabular}{|c|c|c|}
\hline & Ideal Gas Model & 5-species Model \\
\hline $\begin{array}{l}\text { Thermodynamics } \\
\text { Laminar Transport }\end{array}$ & $\gamma=1.4$ & Eq. Stat. Mech. \\
\hline Viscosily & Sutherland's Law & Blottner's Curve Fits \\
\hline Conductivity & $\operatorname{Pr}=0.72$ & Eucken's Relation \\
\hline Mass diffusion & - & Binary, $S c=0.7$ \\
\hline \multicolumn{3}{|l|}{ Turbulent Transport } \\
\hline Viscosity & $\begin{array}{c}\text { Baldwin-Lomax } \\
\text { (with compressibility) }\end{array}$ & $\begin{array}{c}\text { Baldwin-Lomax } \\
\text { (with compressibility) }\end{array}$ \\
\hline Conductivity & $\operatorname{Pr}=0.9$ & $P r_{1}=0.9$ \\
\hline Mass Diffusion & - & $S c_{t}=0.9$ \\
\hline Chemical Kinetics & - & Park Rates \\
\hline Inviscid Flux & Van Leer & Van Leer \\
\hline Accuracy & $3^{\text {rd }}$-Order (MUSCL) & $3^{\text {rd }}$-Order (MUSCL) \\
\hline Limiter & Minmod & Minmod \\
\hline Viscous Flux & Central & Central \\
\hline Accuracy & $2^{\text {nd }}-$ Order & $2^{\text {nLl }}$-Order \\
\hline Wall BC & Isothermal Wall & $\begin{array}{l}\text { Radiative Equilibrium } \\
\text { (fully catalytic wall) }\end{array}$ \\
\hline Time Integration & 2-Factor AF & 2-Factor AF \\
\hline
\end{tabular}

12

American Institute of Aeronautics and Astronautics 
Table 3 Input conditions for all cases in the production airloads matrix

\begin{tabular}{lccccccc}
\hline & $Z(\mathrm{ft})$ & $V_{\infty}(\mathrm{ft} / \mathrm{sec})$ & $q_{\infty}(\mathrm{psf})$ & $M_{\infty}$ & $\rho_{x}\left(\mathrm{slugs} / \mathrm{ft}^{3}\right)$ & $T_{\infty}(\mathrm{R})$ & $\operatorname{Re}(1 / \mathrm{ft})$ \\
\hline Benchmark & - & $2,223.9$ & 374.7 & 3.5 & $1.52 \mathrm{E}-04$ & 168.09 & $2.5 \mathrm{E}+06$ \\
Production & 100,000 & $3,470.6$ & 199.8 & 3.5 & $3.32 \mathrm{E}-05$ & 409.36 & 372,481 \\
Production & 135,000 & $6,280.1$ & 129.5 & 6 & $6.56 \mathrm{E}-06$ & 456.11 & 122,094 \\
Production & 140,000 & $10,553.3$ & 295.3 & 10 & $5.28 \mathrm{E}-06$ & 463.68 & 163,817 \\
Production & 190,000 & $15,708.8$ & 95.88 & 15 & $7.77 \mathrm{E}-07$ & 454.73 & 36,233 \\
\hline
\end{tabular}

Table 4 Mach 3.5 GASP to OADB summary comparison table

\begin{tabular}{ccccc|c|c|c|c|c|c|c|c|}
\hline$M_{\alpha}$ & $\alpha$ & $\delta_{E}$ & $\delta_{B F}$ & $\delta_{S B}$ & $C_{N}$ & $C_{m}$ & $C_{A}$ & $C_{\text {HEI }} C_{H E O} C_{B H F} C_{H S B}$ \\
\hline 3.5 & $40^{\circ}$ & $0^{\circ}$ & $0^{\circ}$ & $69^{\circ}$ & & & & & & & \\
3.5 & $50^{\circ}$ & $0^{\circ}$ & $0^{\circ}$ & $69^{\circ}$ & & & & & & & \\
3.5 & $60^{\circ}$ & $0^{\circ}$ & $0^{\circ}$ & $69^{\circ}$ & & & & & & & \\
3.5 & $40^{\circ}$ & $0^{\circ}$ & $-11.7^{\circ}$ & $69^{\circ}$ & & & & & & & \\
3.5 & $50^{\circ}$ & $0^{\circ}$ & $-11.7^{\circ}$ & $69^{\circ}$ & & & & & & & \\
3.5 & $60^{\circ}$ & $0^{\circ}$ & $-11.7^{\circ}$ & $69^{\circ}$ & & & & & & & \\
3.5 & $40^{\circ}$ & $-10^{\circ}$ & $0^{\circ}$ & $69^{\circ}$ & & & & & & & \\
3.5 & $50^{\circ}$ & $-10^{\circ}$ & $0^{\circ}$ & $69^{\circ}$ & & & & & & & \\
3.5 & $60^{\circ}$ & $-10^{\circ}$ & $0^{\circ}$ & $69^{\circ}$ & & & & & & & \\
\hline
\end{tabular}

Computed data within uncertainty bands of OADB

Computed data slightly outside uncertainty bands of OADB

Computed data well outside uncertainty bands of $O A D B$

Table 5 Mach 6 GASP to OADB summary comparison table

\begin{tabular}{|c|c|c|c|c|c|c|c|c|c|c|c|}
\hline$M_{\infty}$ & $\alpha$ & $\delta_{\varepsilon}$ & $\delta_{B F}$ & $\delta_{S B}$ & $C_{N}$ & $C_{m}$ & $C_{A}$ & $C_{H E I}$ & $C_{\text {HEO }}$ & $C_{\text {HBF }}$ & $C_{H S B}$ \\
\hline 6.0 & $20^{\circ}$ & $0^{\circ}$ & $0^{\circ}$ & $69^{\circ}$ & & & & & & & \\
\hline 6.0 & $30^{\circ}$ & $0^{\circ}$ & $0^{\circ}$ & $69^{\circ}$ & & & & & & & \\
\hline 6.0 & $40^{\circ}$ & $0^{\circ}$ & $0^{\circ}$ & $69^{\circ}$ & & & & & & & \\
\hline 6.0 & $50^{\circ}$ & $0^{\circ}$ & $0^{\circ}$ & $69^{\circ}$ & & & & & & & \\
\hline 6.0 & $60^{\circ}$ & $0^{\circ}$ & $0^{\circ}$ & $69^{\circ}$ & & & & & & & \\
\hline
\end{tabular}

Computed data within uncertainty bands of OADB

Computed data slightly outside uncertainty bands of OADB

Computed data well outside uncertainty bands of OADB 
Table 6 Computed aerodynamic force and moment coefficients for Mach 15

\begin{tabular}{ccccccccc}
\hline$\alpha$ & & & $C_{N}$ & $C_{A}$ & $C_{m}$ & $C_{H E I}$ & $C_{H E O}$ & $C_{H B F}$ \\
\hline $30^{\circ}$ & Pressure Only & Laminar & 0.7519 & 0.0499 & 0.0009 & -0.0788 & -0.0454 & -0.1563 \\
& Total & Laminar & 0.7529 & 0.0582 & 0.0002 & -0.0790 & -0.0455 & -0.1567 \\
& Total & Turbulent & 0.7622 & 0.0800 & -0.0078 & -0.0870 & -0.0479 & -0.1591 \\
4 & Pressure Only & Laminar & 1.1757 & 0.0541 & -0.0181 & -0.1483 & -0.0738 & -0.2681 \\
& Total & Laminar & 1.1770 & 0.0630 & -0.0189 & -0.1488 & -0.0741 & -0.2678 \\
& Total & Turbulent & 1.1874 & 0.0885 & -0.0232 & -0.1555 & -0.0763 & -0.2720 \\
\hline
\end{tabular}

Table 7 Mach 15 GASP to OADB summary comparison table

\begin{tabular}{|c|c|c|c|c|c|c|c|c|c|c|c|}
\hline$M_{\infty}$ & $\alpha$ & $\delta_{E}$ & $\delta_{B F}$ & $\delta_{S B}$ & $\overline{C_{N}}$ & $\overline{C_{m}}$ & $\overline{C_{A}}$ & $C_{H E I}$ & $C_{H E O}$ & $C_{B H F}$ & $C_{H S B}$ \\
\hline 15.0 & $30^{\circ}$ & $0^{\circ}$ & $0^{\circ}$ & $0^{\circ}$ & & & & & & & \\
\hline 15.0 & $40^{\circ}$ & $0^{\circ}$ & $0^{\circ}$ & $0^{\circ}$ & & & & & & & \\
\hline 15.0 & $50^{\circ}$ & $0^{\circ}$ & $0^{\circ}$ & $0^{\circ}$ & & & & & & & \\
\hline 15.0 & $60^{\circ}$ & $0^{\circ}$ & $0^{\circ}$ & $0^{\circ}$ & & & & & & & \\
\hline 15.0 & $30^{\circ}$ & $0^{\circ}$ & $+10^{\circ}$ & $0^{\circ}$ & & & & & & & \\
\hline 15.0 & $40^{\circ}$ & $0^{\circ}$ & $+10^{\circ}$ & $0^{\circ}$ & & & & & & & \\
\hline 15.0 & $50^{\circ}$ & $0^{\circ}$ & $+10^{\circ}$ & $0^{\circ}$ & & & & & & & \\
\hline 15.0 & $60^{\circ}$ & $0^{\circ}$ & $+10^{\circ}$ & $0^{\circ}$ & & & & & & & \\
\hline 15.0 & $30^{\circ}$ & $+10^{\circ}$ & $0^{\circ}$ & $0^{\circ}$ & & & & & & & \\
\hline 15.0 & $40^{\circ}$ & $+10^{\circ}$ & $0^{\circ}$ & $0^{\circ}$ & & & & & & & \\
\hline 15.0 & $50^{\circ}$ & $+10^{\circ}$ & $0^{\circ}$ & $0^{\circ}$ & & & & & & & \\
\hline 15.0 & $60^{\circ}$ & $+10^{\circ}$ & $0^{\circ}$ & $0^{\circ}$ & & & & & & & \\
\hline 15.0 & $30^{\circ}$ & $-10^{\circ}$ & $0^{\circ}$ & $0^{\circ}$ & & & & & & & \\
\hline 15.0 & $40^{\circ}$ & $-10^{\circ}$ & $0^{\circ}$ & $0^{\circ}$ & & & & & & & \\
\hline 15.0 & $50^{\circ}$ & $-10^{\circ}$ & $0^{\circ}$ & $0^{\circ}$ & & & & & & & \\
\hline 15.0 & $60^{\circ}$ & $-10^{\circ}$ & $0^{\circ}$ & $0^{\circ}$ & & & & & & & \\
\hline
\end{tabular}

Computed data within uncertainty bands of $\mathrm{OADB}$

Computed data slightly outside uncertainty bands of OADB

Computed data well outside uncertainty bands of OADB 


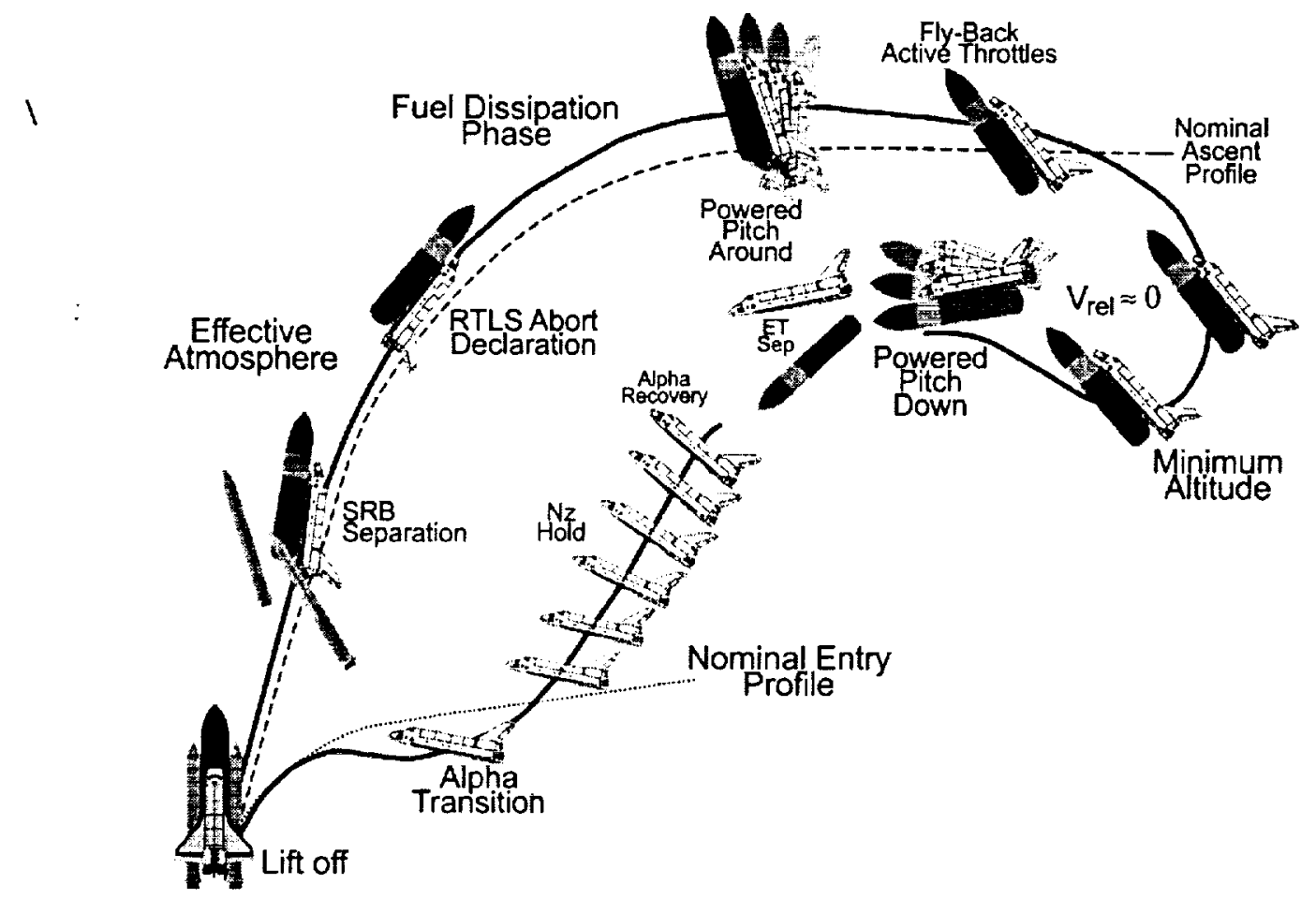

Fig. 1 Return to launch site (RTLS) abort trajectory.

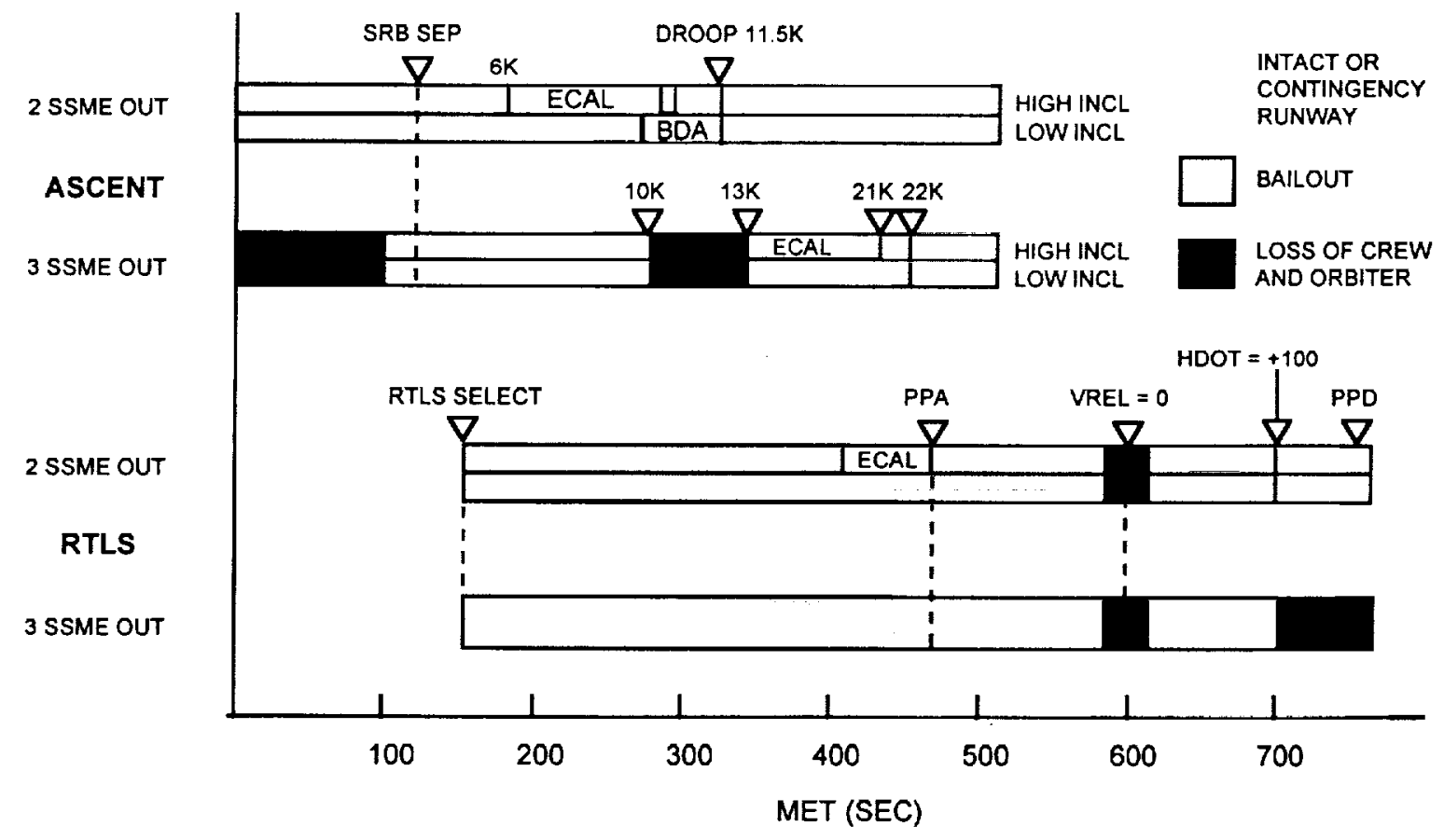

Fig. 2 Current abort black zones for two- and three-engine failures during launch. 


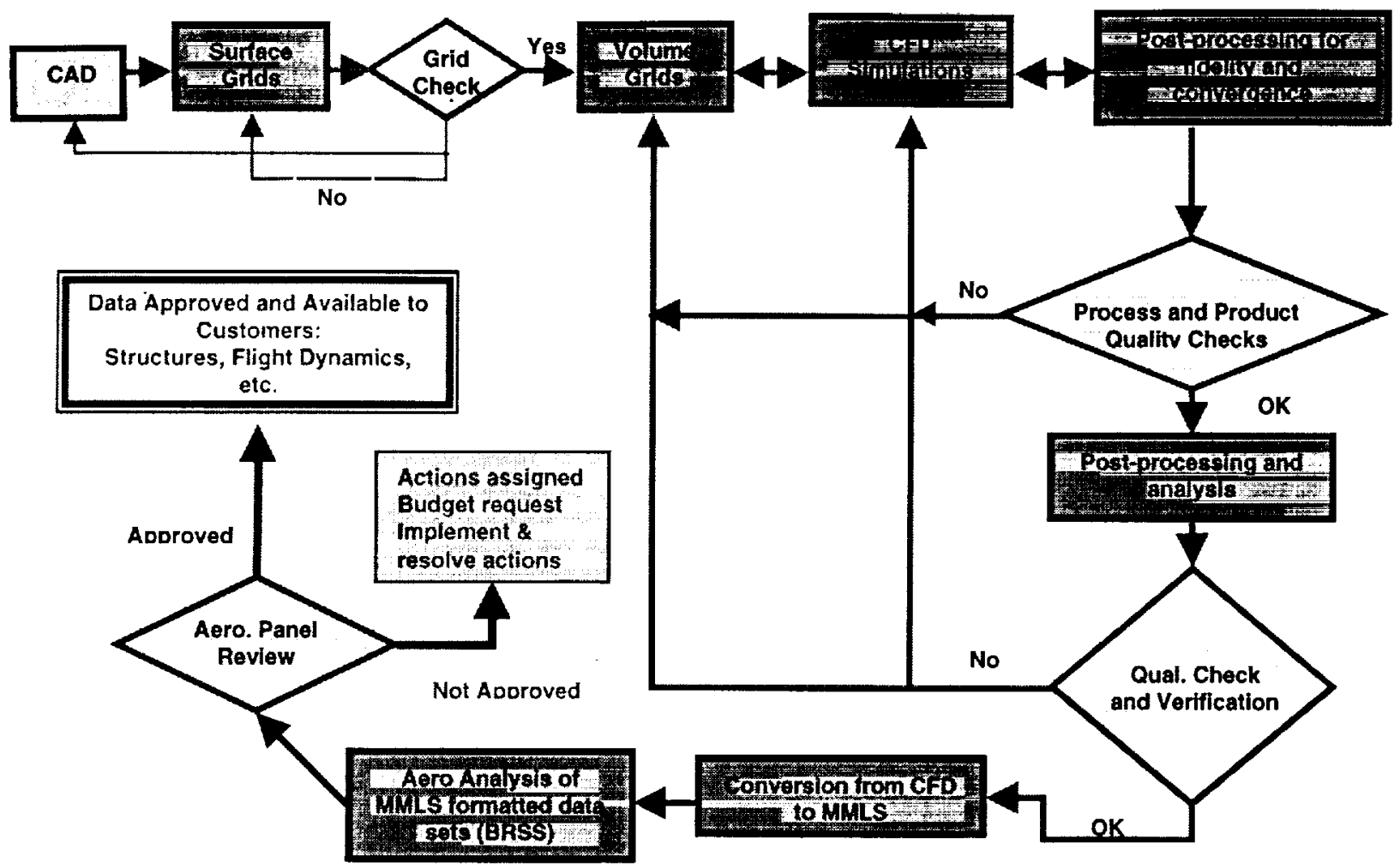

Fig. 3 Overview of the NASA-ARC approach.
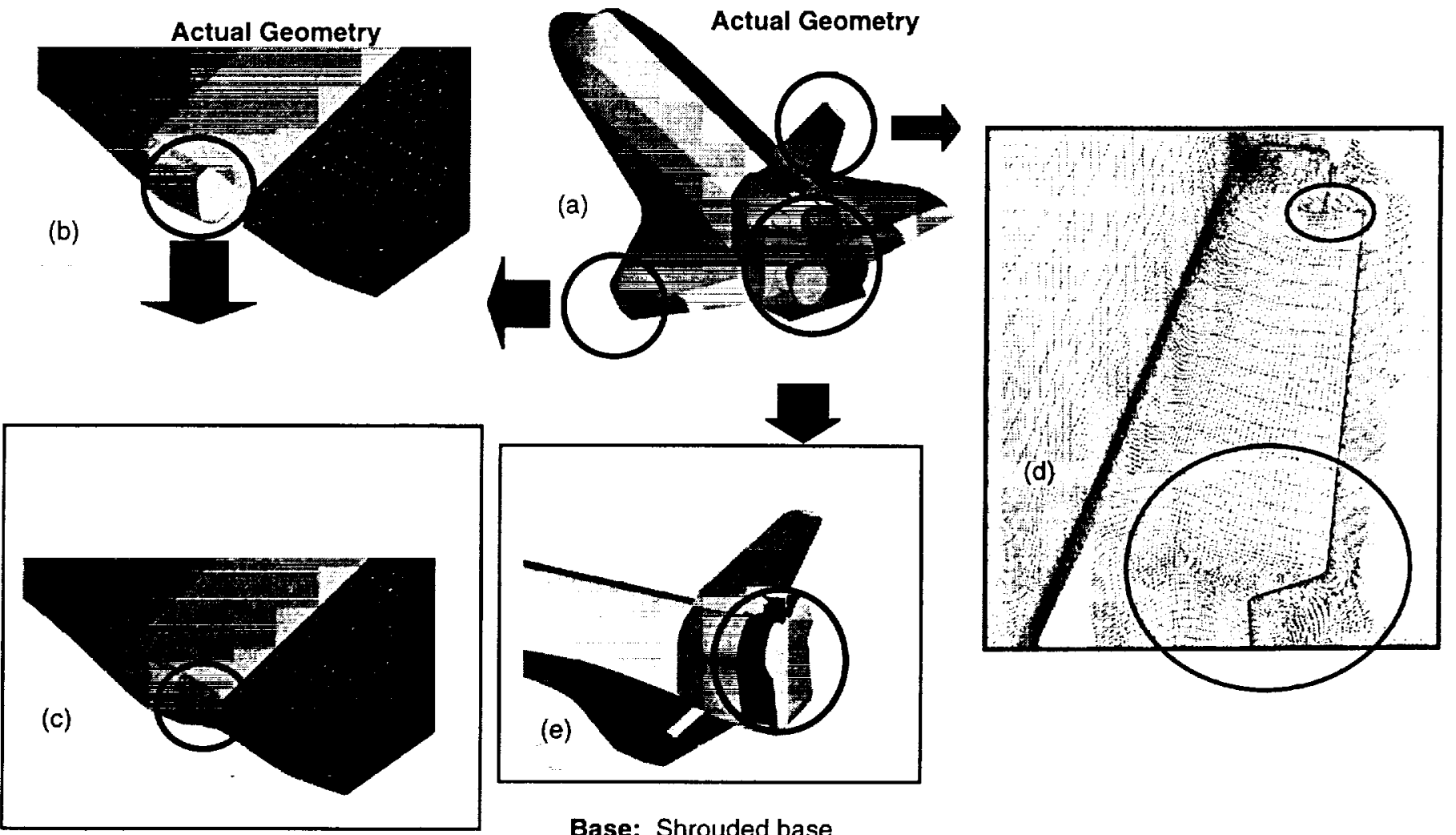

Wing Tip: Edge Fairing

Base: Shrouded base

Fig. 4 Geometric approximations. 
(a) Topology Layers:

- Inner - Near surface (wrap-around) topology

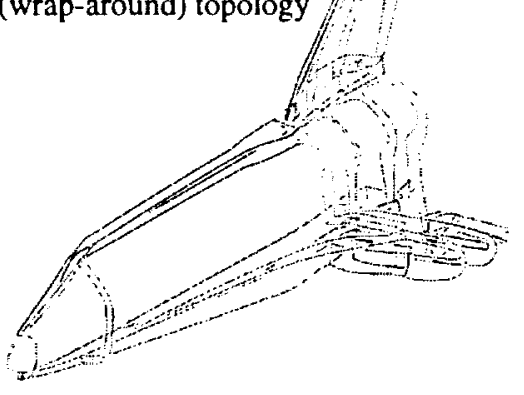

(b) Topology Layers:

- Intermediate

- Inner

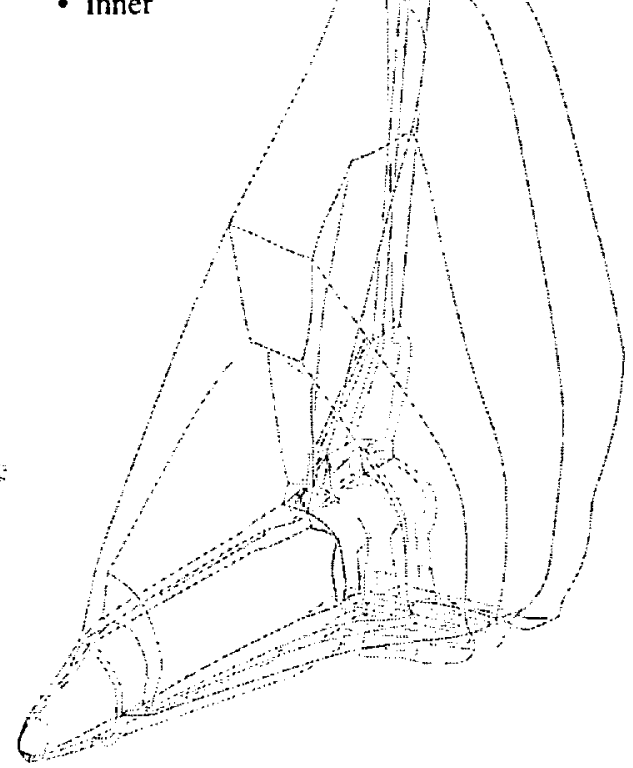

(c) Topology Layers:

- Outer

- Intermediate

- Inner

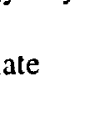

Fig. 5 Multi-layer grid generation strategy.

(b) Inner layer grid topology

(c) Replaceable: Control surface topology systems (a) Local elevons and gap topology

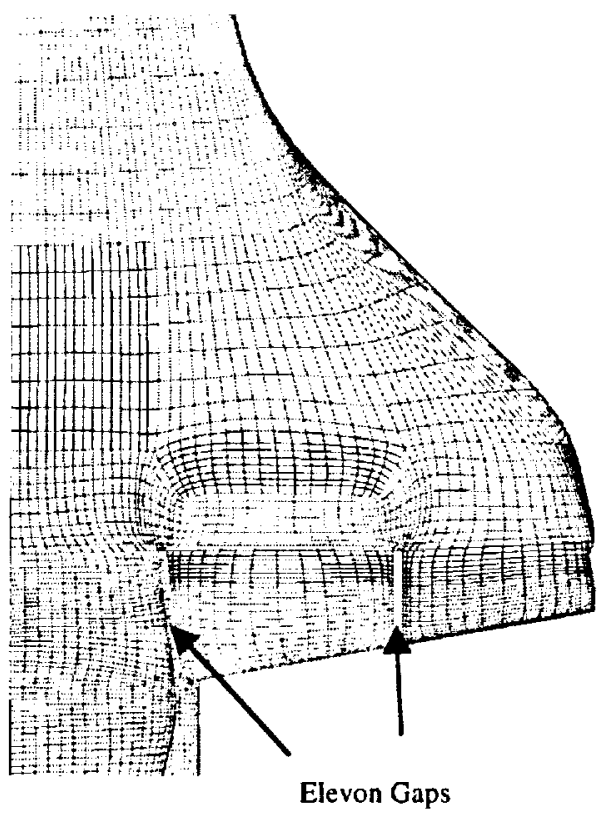

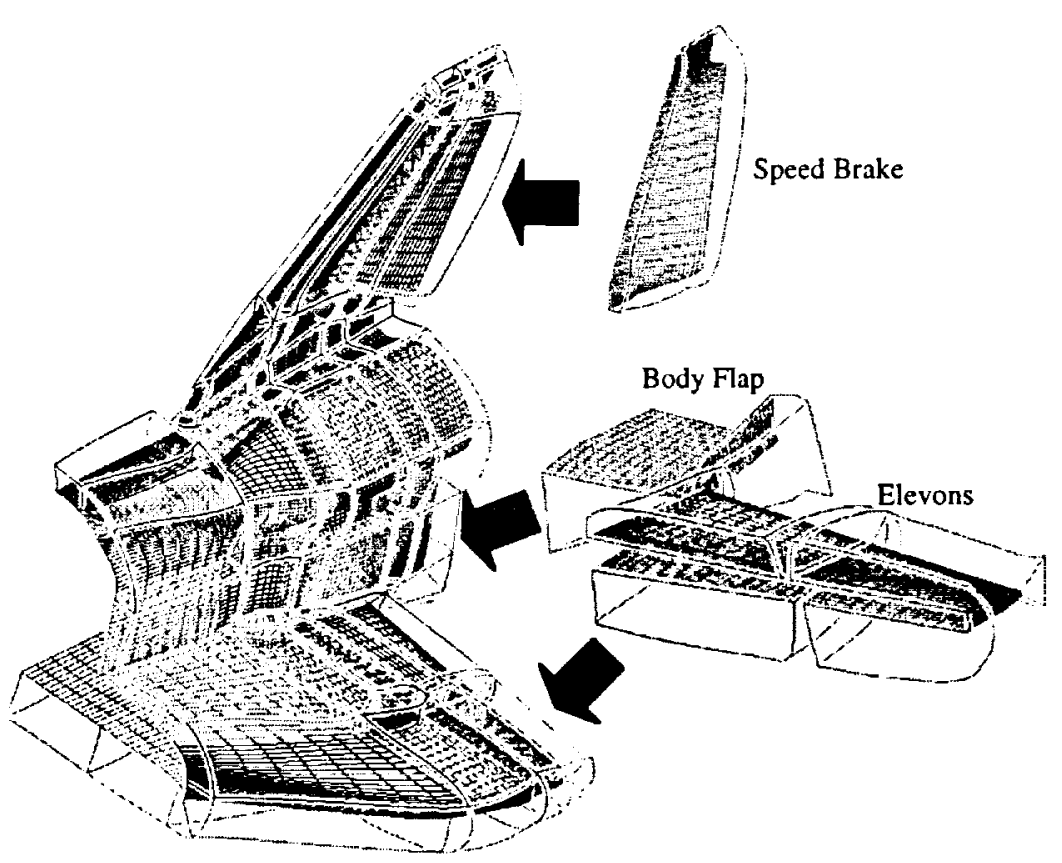

Fig. 6. Grid generation strategy: (a) surface grid smoothness and gap topology;

(b) viscous inner-layer grid topology; and (c) replaceable control surfaces. 


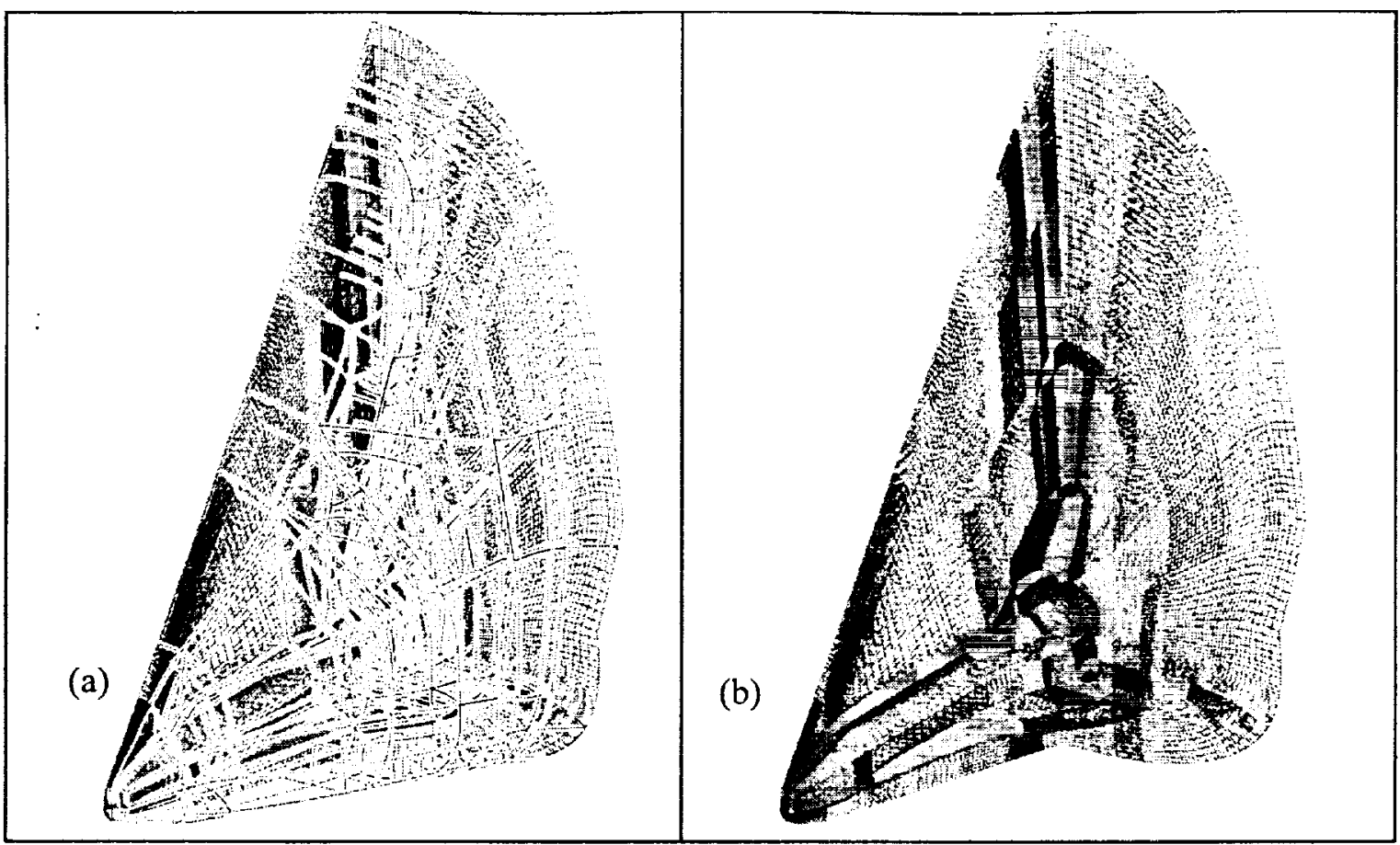

Fig. 7 ARC volume grid (2.2 million points without the wake grid - wake grid added 1.4 million points): (a) topological morphology, (b) 365 non-merged blocks.
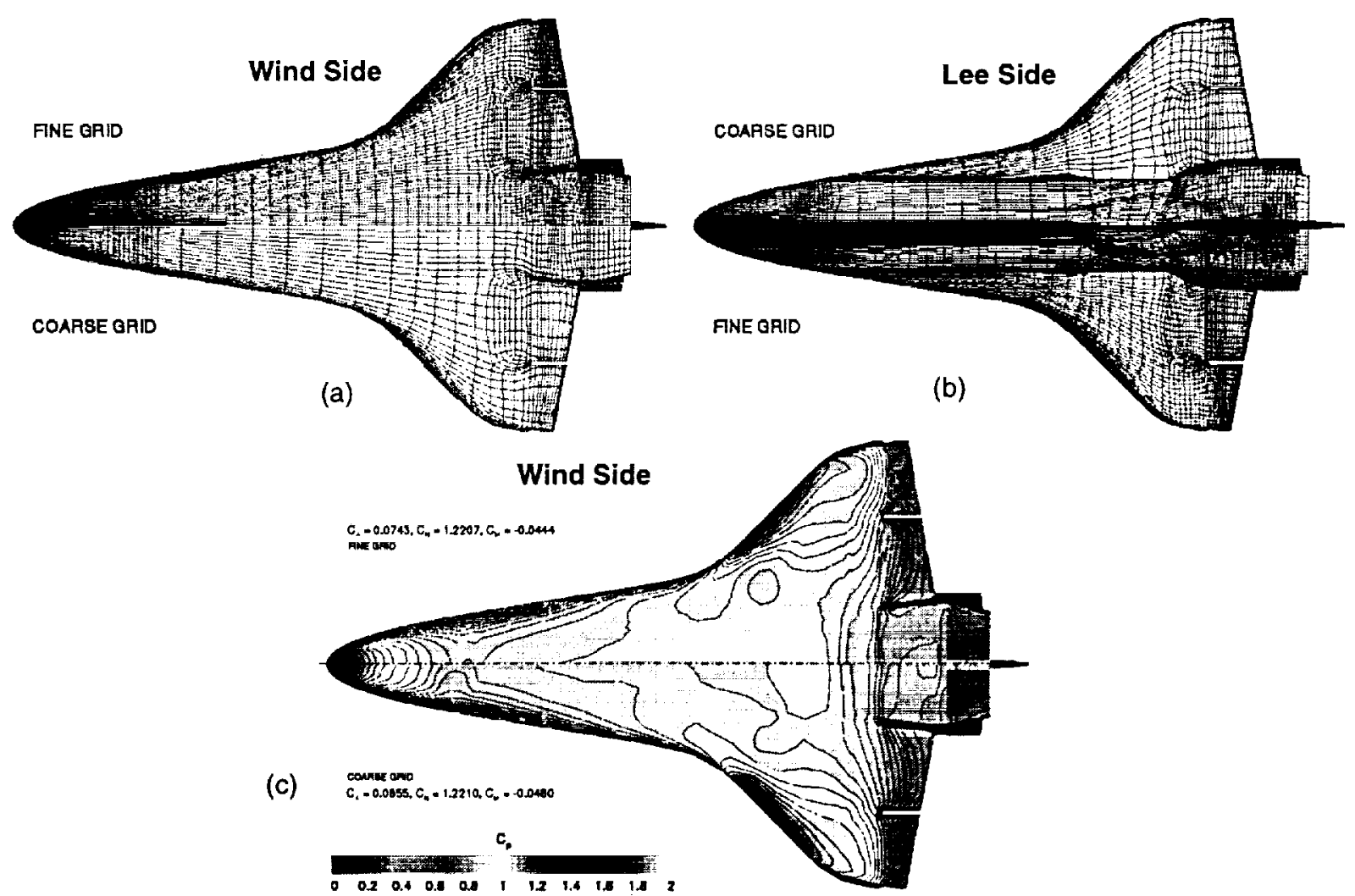

Fig. 8 Baseline grid fidelity verification: (a) wind-side comparisons of coarse (275K pts.) and fine (2.2M pts.) grid sequence levels; (b) lee-side comparisons; and (c) Mach 10 angle of attack $40^{\circ}$ comparison of computed surface $C_{p}$ between coarse and fine grids. 
Summary: 3450 ileratione

$\operatorname{Max}=0.02$

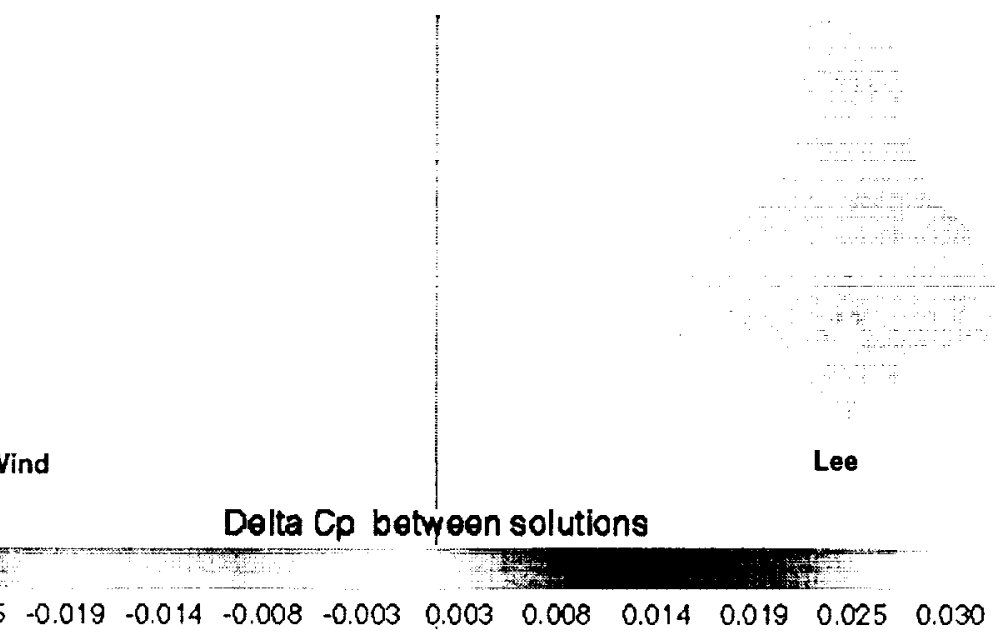

Fig. 9 Example of steady-state surface pressure coefficient convergence monitoring

(Mach 3.5 angle of attack $18.5^{\circ}$ tunnel simulation.)
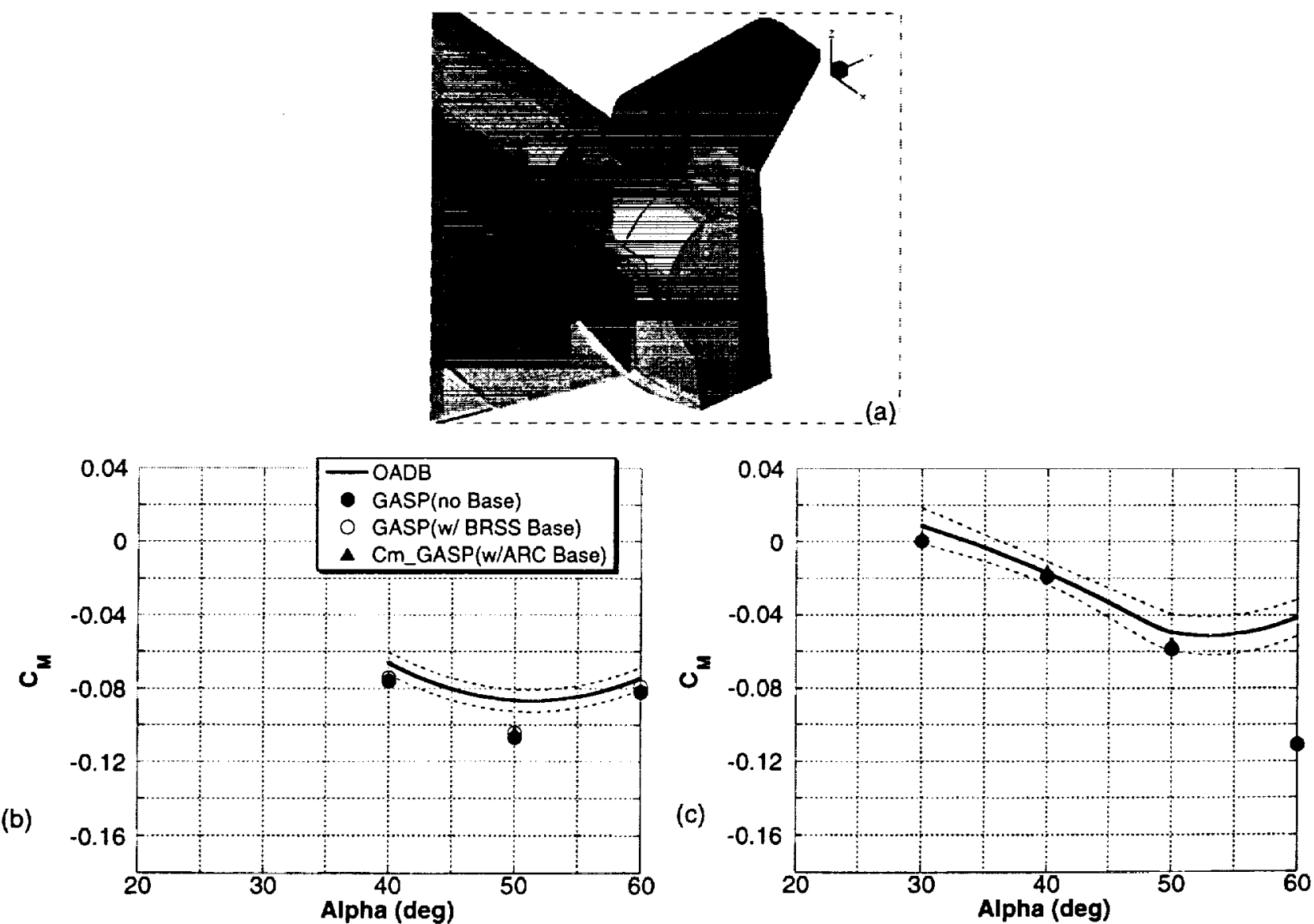

Fig. 10 Impact of base geometry approximation on pitching moment: (a) schematic of the base shroud simplification; (b) BRSS base correction contributions to pitching moment at Mach 3.5; and (c) BRSS base correction contributions to pitching moment at Mach 15. 


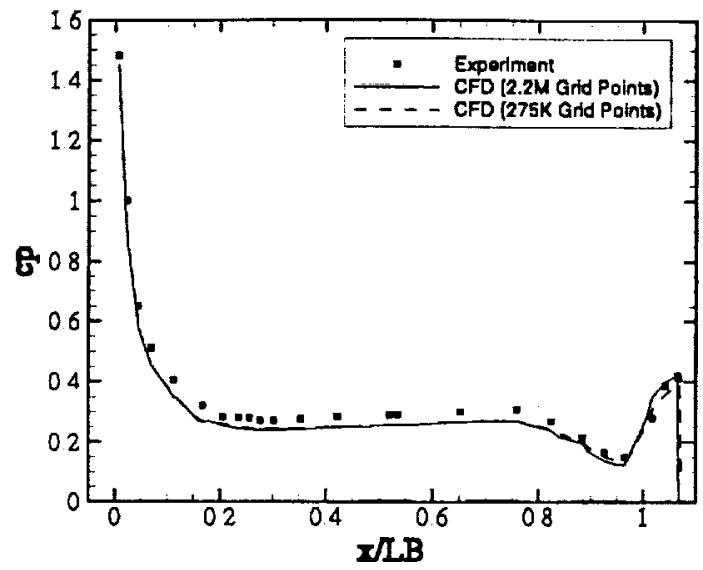

Fig. 11 GASP to wind tunnel experimental data wind centerline comparison at Mach 3.5 and angle of attack of $18.5^{\circ}$.

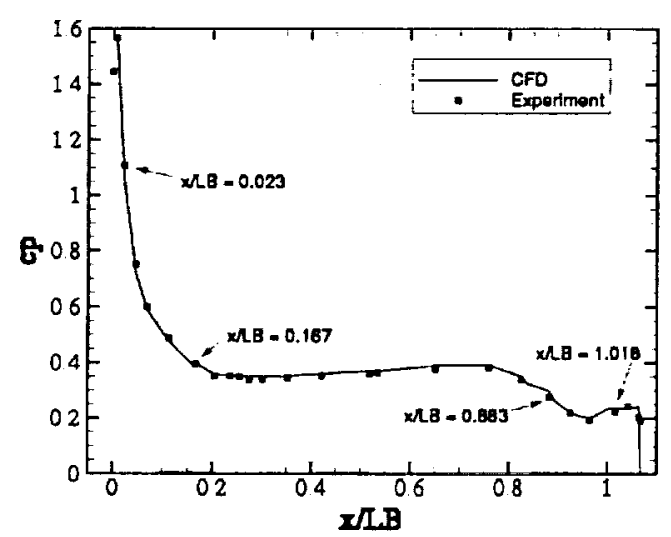

(a)

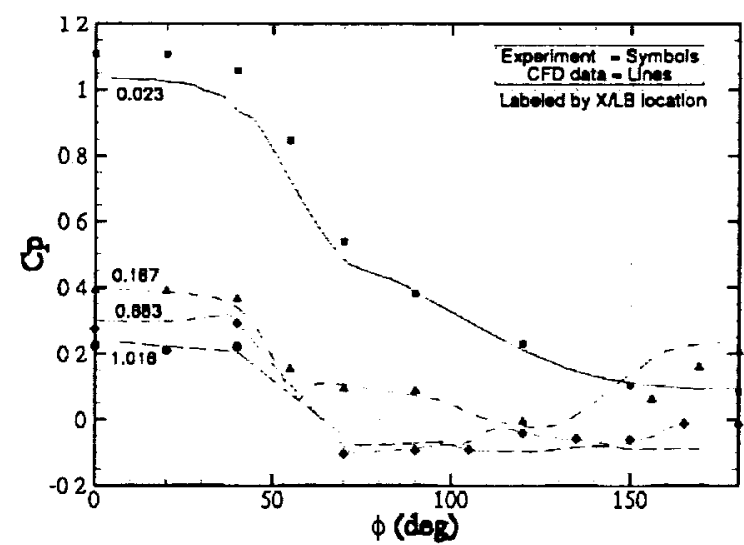

(b)

Fig. 12 GASP to wind tunnel experimental data comparison at Mach 3.5 and angle of attack of $23.2^{\circ}$ : (a) wind centerline comparison; and (b) circumferential cuts. 

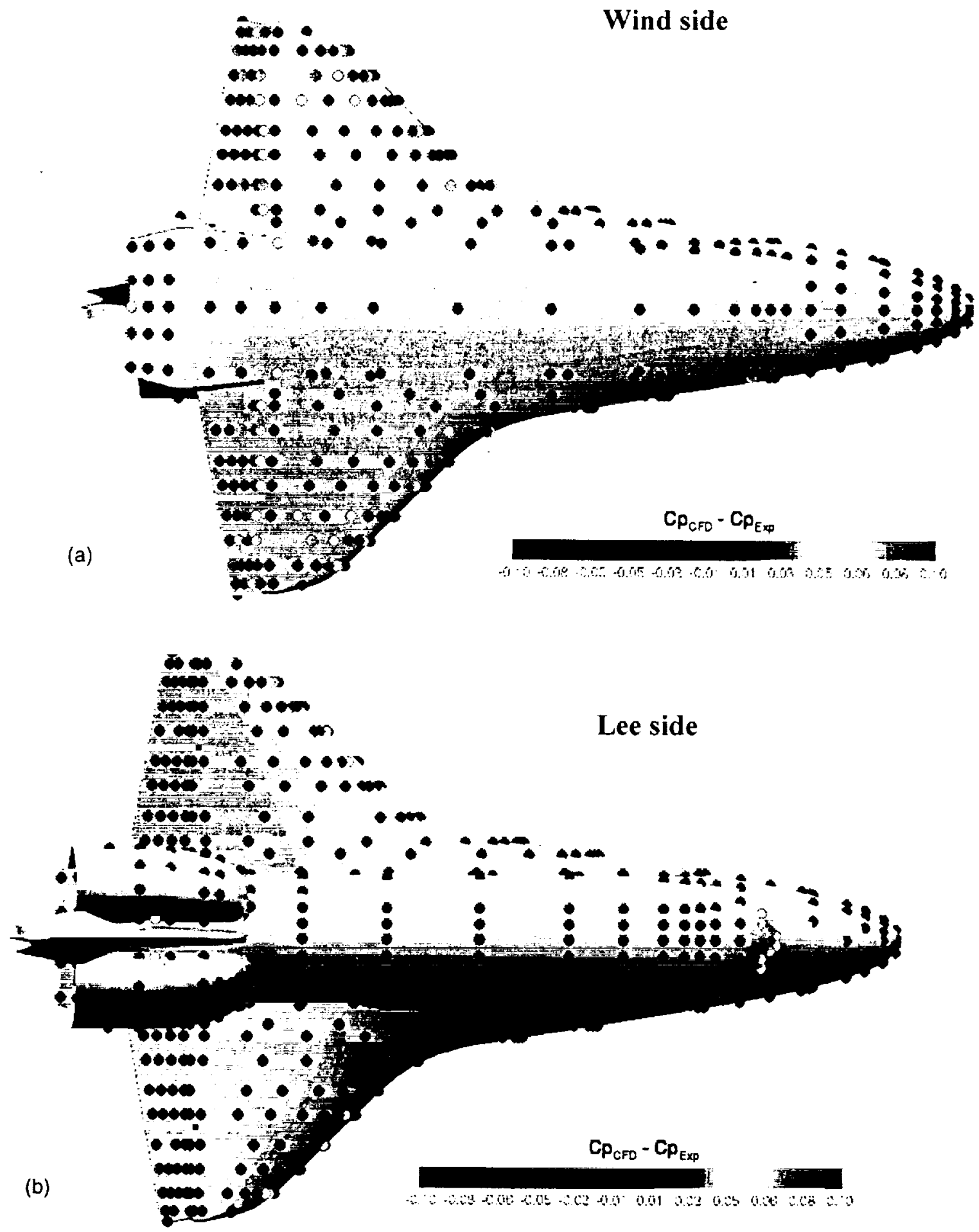

Fig. 13 GASP to experimental data surface pressure coefficient differences at the data-port locations for the Mach 3.5 and angle of attack $23.2^{\circ}$ tunnel case: (a) wind side; and (b) lee side. 

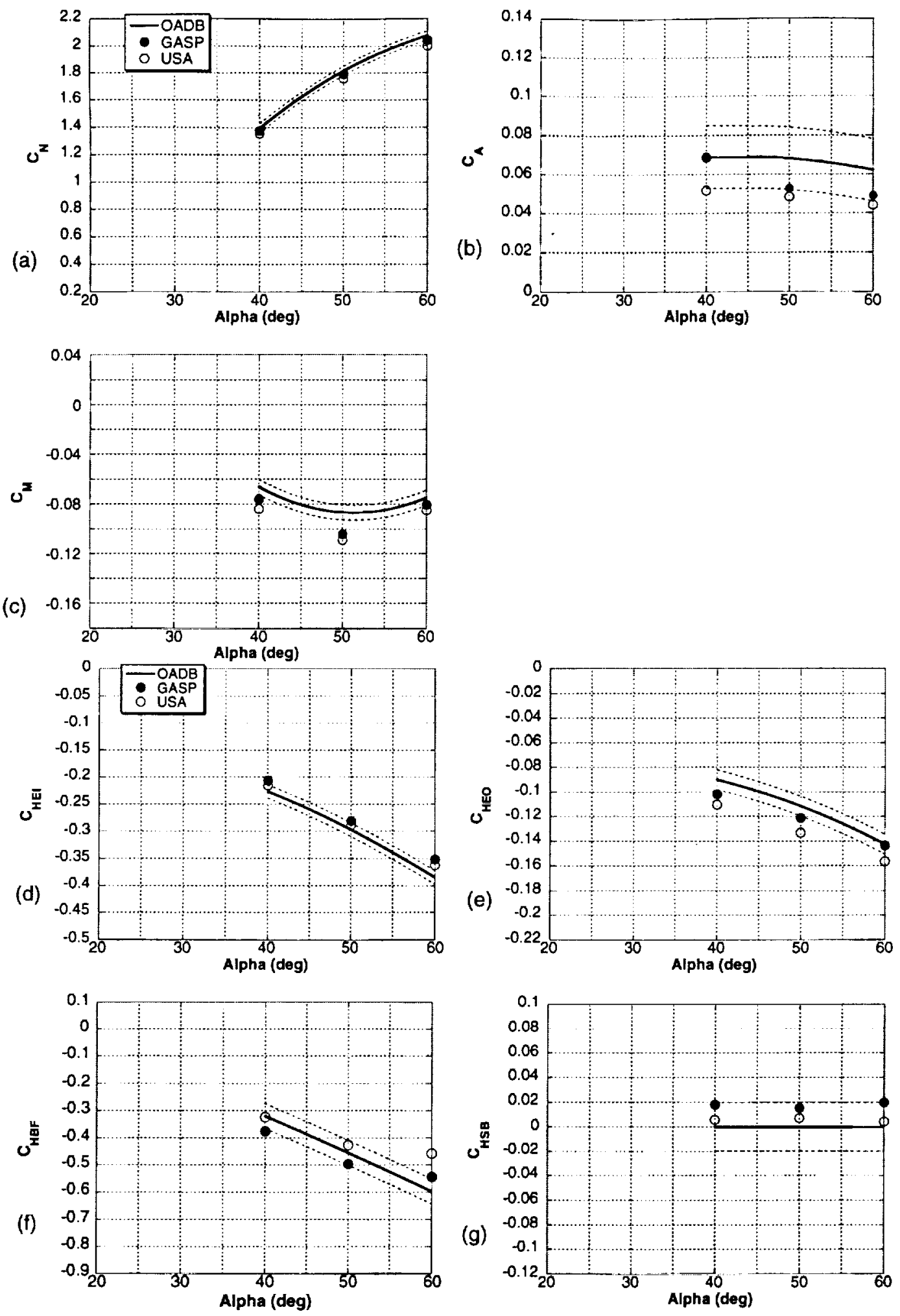

Fig. 14 Integrated load and moment comparisons between GASP and OADB at Mach 3.5, $\delta_{E}=0^{\circ}, \delta_{B r}=0^{\circ}, \delta_{S B}=69.76^{\circ}$ : (a) normal force coefficients; (b) axial force coefficients; (c) pitching moments; (d) inboard elevon hinge moments; (e) outboard elevon hinge moments; (f) body flap hinge moment; and (g) speed brake hinge moments. 

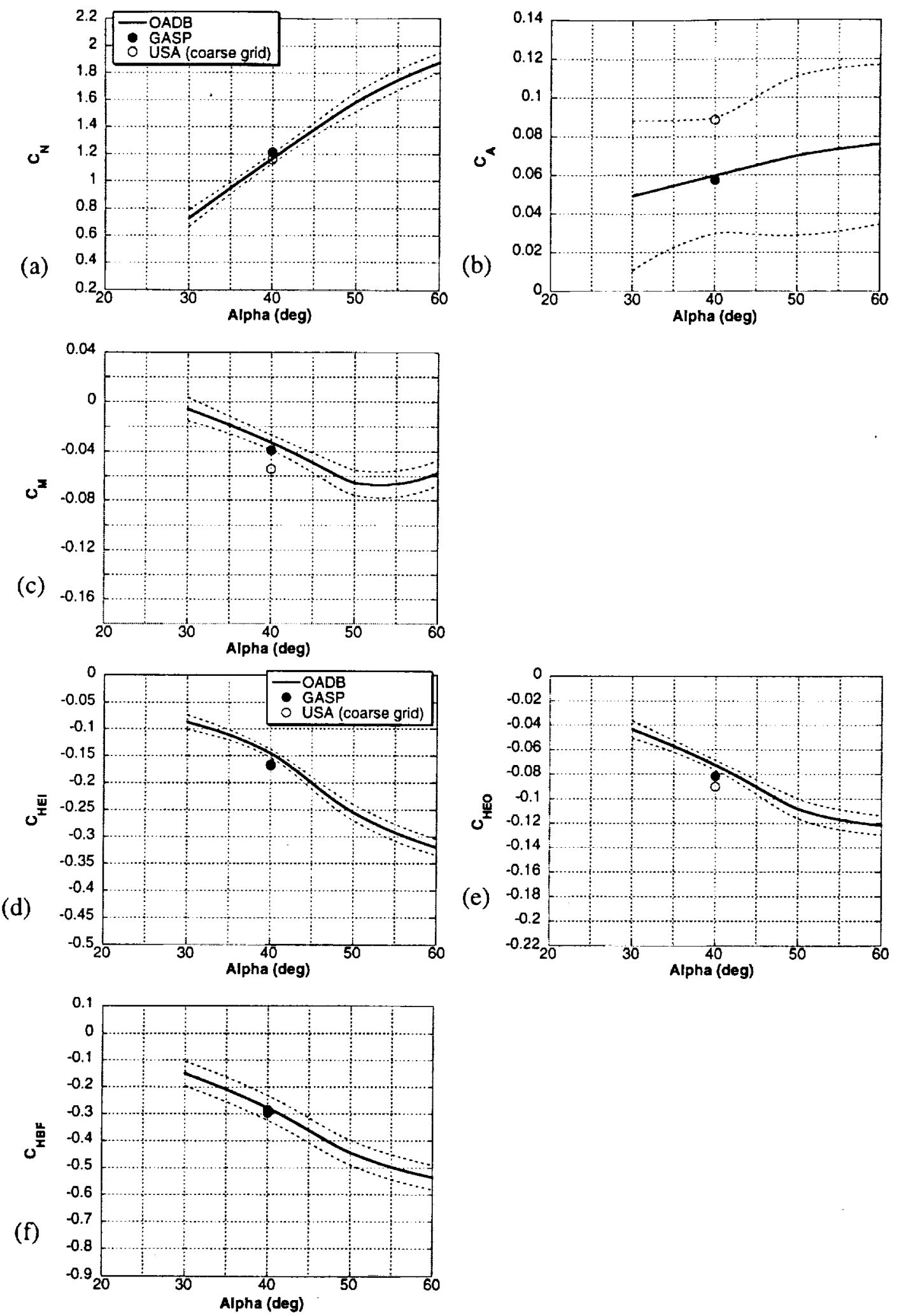

Fig. 16. Integrated load and moment comparisons between GASP and OADB at Mach 10 (real gas), $\delta_{E}=0^{\circ}, \delta_{B F}=0^{\circ}, \delta_{S B}=0^{\circ}$ : (a) normal force coefficients; (b) axial force coefficients; (c) pitching moments; (d) inboard elevon hinge moments; (e) outboard elevon hinge moments; and (f) body flap hinge moment. 
(a)
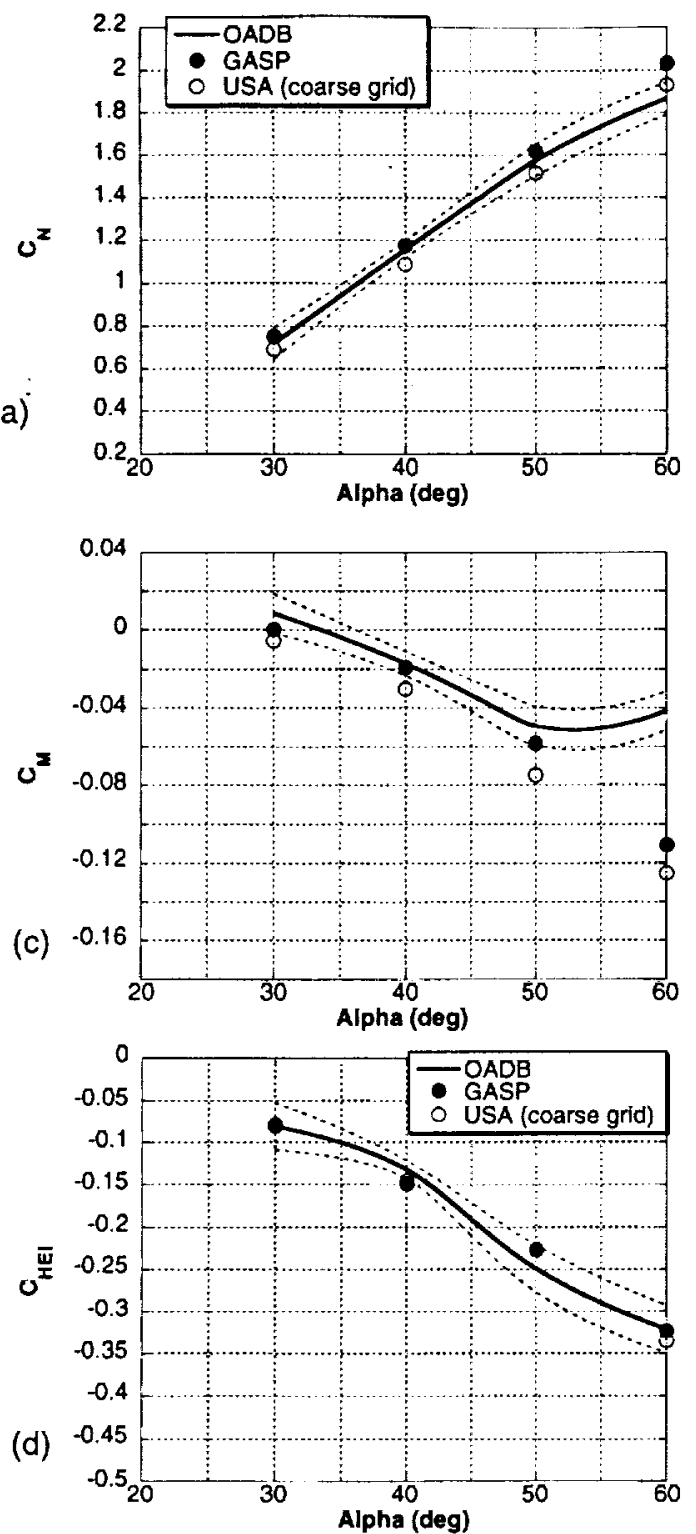

(e)

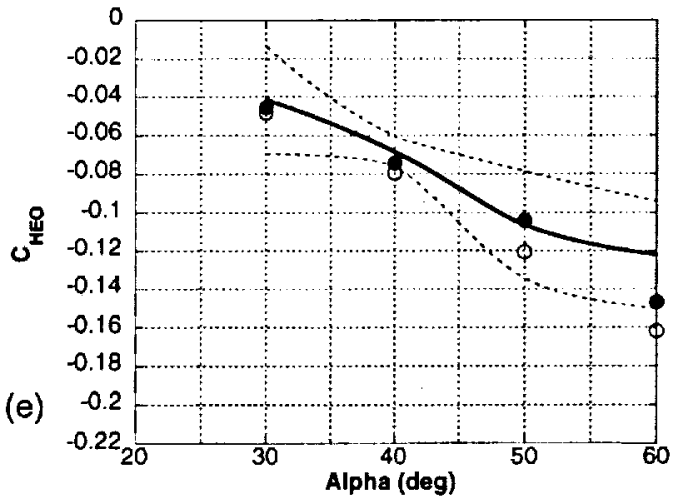

(b)

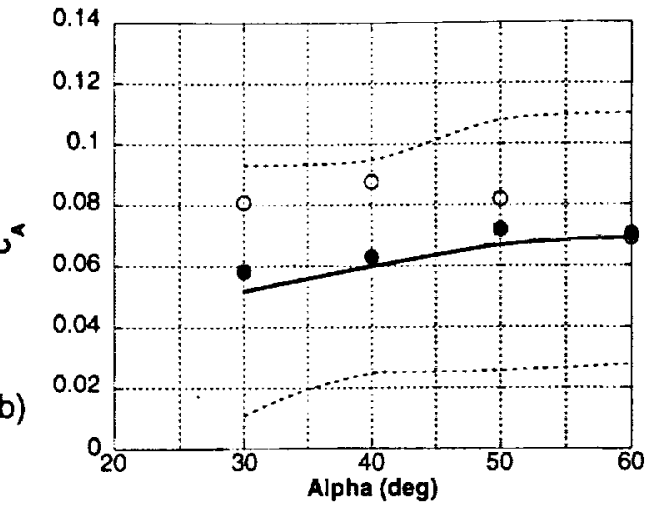

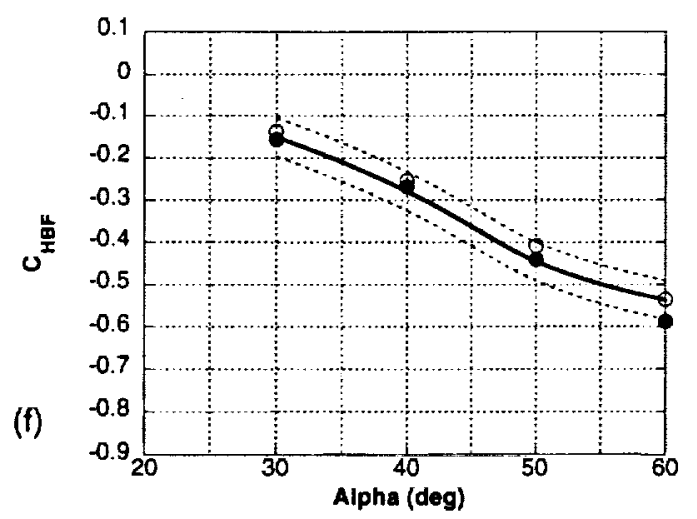

